\title{
Inhalation therapy in the next decade: Determinants of adherence to treatment in asthma and COPD
}

Proceedings of the European Seminars in Respiratory Medicine course, Inhalation therapy in the next decade: Determinants of adherence to treatment in asthma and COPD, held in Taormina, Italy, on 3-4 March, 2017

Claudio F. Donner1,2, Sandro Amaducci2, Elena Bacci³, Sandra Baldacci4, Maria L. Bartoli3, Gianfranco M. Beghi 5 , Alida Benfante 6 , Sara Brighindi3 ${ }^{3}$ Lucio Casali7, Daniela Castiglia 6 , Mario Cazzola ${ }^{8}$, Alessandro Celi 3 , Silvana Cianchetti ${ }^{3}$, Giorgio Colombo9, Claudia Crimi'10, Federico L. Dente3, Giuseppe Di Maria11, Annalisa Di Maria12, Manuela Latorre3, Federico Lavorini14, Sara Maio4, Claudia Mannini6, Riccardo Messina6, Pier Luigi Paggiaro33, Patrizia Pignatti13, Massimo Pistolesi14, David Price15,16, Nicola Scichilone6, Marzia Simoni4, Antonio Spanevello17,18, Martina Stagno d'Alcontres ${ }^{15}$, Shwana Tan ${ }^{15}$, Roberto Torchio'19, Giovanni Viegi 4,20, Dina Visca17, Emiel F.M. Wouters21, Shaylynn Yu Hui Xin ${ }^{15}$

1 Mondo Medico, Multidisciplinary and Rehabilitation Outpatient Clinic, Borgomanero, Italy

2 Mondo Respiro Foundation, Borgomanero, Italy

3 Cardio-Thoracic and Vascular Department, Respiratory Pathophysiology Unit, University of Pisa, Italy

4 Pulmonary Environmental Epidemiology Unit, CNR Institute of Clinical Physiology, Pisa, Italy

5 Unit of Pulmonary Rehabilitation, Casorate Primo Hospital, Casorate Primo, Italy

${ }^{6}$ Biomedical Department of Internal and Specialist Medicine, University of Palermo, Italy

7 Former full Professor of Respiratory Diseases at the University of Perugia, Italy

8 Chair of Respiratory Medicine, Department of Systems Medicine, University of Rome Tor Vergata, Italy

9 Department of Drug Sciences, University of Pavia, Italy

10 Intensive Respiratory Care Unit, Cannizzaro Hospital, Catania, Italy

11 Department of Clinical and Experimental Medicine, Section of Respiratory Diseases,

University of Catania, Italy

12 Independent Pulmonologist and General Practitioner Trainee, Catania, Italy

13 Allergy and Immunology Unit, Respiratory Medicine Unit, Istituti Clinici Scientifici Maugeri IRCCS, Pavia, Italy

14 Department of Experimental and Clinical Medicine, Careggi University Hospital, Florence, Italy

15 Observational and Pragmatic Research Institute Pte Ltd. (OPRI), Singapore

16 Academic Primary Care, University of Aberdeen, Polwarth Building, Foresterhill, Aberdeen, UK

17 Respiratory Medicine Unit, Istituti Clinici Scientifici Maugeri IRCCS, Tradate, Italy

18 Department of Medicine and Surgery, Respiratory Diseases, University of Insubria, Varese-Como, Italy

19 Respiratory Physiopathology Laboratory and Sleep Respiratory Disorders Centre, University Teaching

Hospital "S. Luigi", Orbassano, Italy

20 Acting Director, CNR Institute of Biomedicine and Molecular Immunology "Alberto Monroy", Palermo, Italy

21 Department Respiratory Medicine, Maastricht University Medical Center, The Netherlands

Corresponding author: Dr. Claudio F. Donner, Mondo Medico, Via Monsignor Cavigioli 10, 28021 Borgomanero (NO), Italy. Tel. +39.0322.836718. E-mail: cfdonner@mondomedico.it

Key words: European Seminars in Respiratory Medicine; Inhalation therapy; COPD.

Received for publication: 28 August 2017

Accepted for publication: 18 December 2017

CC Copyright C.F. Donner et al., 2018

Tipografia PI-ME Editrice, Italy

Monaldi Archives for Chest Disease 2018; 88:886

doi: 10.4081/monaldi.2018.886

This article is distributed under the terms of the Creative Commons Attribution Noncommercial License (by-nc 4.0) which permits any noncommercial use, distribution, and reproduction in any medium provided the original author(s) and source are credited.

\section{Introduction}

The European Seminars in Respiratory Medicine has represented an outstanding series updating new science in respiratory disease from the 1990's up to the early beginning of this $21^{\text {st }}$ century $[1,2]$. Its aim is to start a new series updating issues and current science, focusing on the multidisciplinary approach to patients with respiratory disease [3]. As such, it represents a unique opportunity for specialists in Respiratory Medicine involved in Basic and Clinical Research to discuss topics and debated problems in medical care, at a top level forum guided by an expert panel of authors.

The structure of the seminar is based on the following pillars:

- Attendance at the Seminars is strictly limited: selection of participants is based, in order of priority, on scientific curriculum, age (younger specialists are privileged), and early receipt of the application form. 
- For each topic is allotted considerable time for presentation and discussion. The first section is devoted to a series of presentations (with adequate time allocated for discussion) by an expert panel of researchers and clinicians. In the second section involves discussions of controversial issues, in a smaller audience format encouraging interaction between the panel and audience.

- "Meet the expert" seminars discuss topical subjects in more depth, utilizing an interactive tutorial.

The Seminar is accredited to provide continuing medical education (CME) for Italian physicians, with approval of up to 100 participants, providing $13 \mathrm{CME}$ credits to professionals in the following specialties: Allergology and Immunology, Anestesiology, Cardiology, Geriatrics, General Practice, Internal Medicine, Pulmonology, Radiology, Rehabilitation, Rheumatology, and Thoracic Surgery.

The seminar faced the hot topic of inhalation therapy with an effective multidisciplinary approach aimed to evaluate, with particular regard, the determinants of adherence to treatment, representing a critical issue in the management of chronic airway diseases. In asthma and COPD, the adherence to treatment, representing a pivotal aspect in long term care, is usually poor, also according to the Italian Ministry of Health reports. Therefore, the assessment of the causes of this negative behavior and a correct approach to try to solve this open problem represent a very important issue in the long-term management of these chronic diseases

The objectives of this Seminar were:

- Description of the current situation and open problems in asthma and chronic obstructive pulmonary disease (COPD).

- Analysis of currently available inhalation drugs and the role played according to specific phenotype.

- Discussion of the specific role of inhaler devices in patient management.

- Provision of several innovative examples of management approaches aimed to improve adherence to treatment.

\section{Epidemiology of obstructive lung disease and adherence to treatment in asthma and COPD in Italy}

The first epidemiological parameter, taken into account for health policies, is mortality. Analyzing twenty years of national statistics, it has been recently shown that the difference between cardiovascular and respiratory deaths has decreased in Italy from 479 to 252 per 100,000 from 1990 to 2014 [4]. In such a year, there were 41,397 deaths for respiratory diseases: of them, 20,181 were due to chronic diseases of lower airways (429 asthma).

The World Health Organization (WHO) European Detailed Mortality Database [5] (updated July 2016) indicates that Italy ranks $24^{\text {th }}$ out of 43 countries for age standardized death rate $(12.8$ per 100,000$)$ due to bronchitis/emphysema / other COPD, whilst $10^{\text {th }}$ out of 39 for respiratory failure (1.5 per 100,000). Differently, Italy ranked third to last out of 43 countries for age standardized death rate $(0.32$ per 100,000$)$ due to asthma.

The second epidemiological parameter, taken into account for health policies, is morbidity. The WHO European Hospital Morbidity Database [6] indicates that Italy ranks four to last out of 33 countries for in-patients per 1000 populations due to COPD (1.1) and second to last due to asthma (0.2). However, the COPD data are very much influenced by the political decision of many health authorities considering as inappropriate a diagnosis of COPD from hospital discharge. Thus, the analysis of the respiratory diagnoses related groups data in the Ministry of Health database [7] shows that, differently from most western countries, COPD decreased in Italy since 1999 (about 140000 hospital discharges) to 2014 (about 40000 hospital admissions), whilst the code
"Respiratory failure / Pulmonary edema" increased in the same period from less than 20000 to near 140000 hospital admissions, overcoming in 2012 the code "Pneumonia / pleuritis" and thus ranking first among all respiratory hospital admissions.

Analyzing the relevant epidemiological literature of the period 1960 2007, it was highlighted a COPD prevalence increase from around 6 to around $9 \%$ [8]. Such figure has continued to increase up to $12.0 \%$ in the WHO European region [9].

The European Respiratory Society spirometry tent data [10] has confirmed an increasing trend of airflow obstruction by age after 40 years, with an overestimate determined by the wrong fixed ratio criterion $v s$ the correct lower limit of normal criterion. However, the figures from other information sources tend to under-estimate COPD prevalence: e.g. the December 2015 Health Survey organized by National Institute of Statistics (ISTAT), that collected data through at-home administered interviews to the components of 60.000 households distributed throughout the national territory, showed a national prevalence of $3.78 \%$, with wide regional variations (Abruzzo and Sardinia: about 5\%; Trentino Alto Adige about 2.5\%).

Also the 2008-2012 Health Examination Survey conducted by the National Institute for Health (ISS) showed underestimated values of COPD prevalence rates: e.g., $5 \%$ in men and $3.4 \%$ in women aged $50-69$ years.

Indeed, the respiratory epidemiological studies carried out by $\mathrm{Na}-$ tional Research Council (CNR) in general population samples living in Po Delta and Pisa areas since the ' 80 s had shown in men prevalence rates of chronic cough and phlegm over $20 \%$ and of medical diagnoses of chronic bronchitis and emphysema between 5 and 7\% [11]. Such studies were also the basis to ascertain the overlap of asthma, chronic bronchitis and emphysema, with or without airflow obstruction, through a Proportional Venn Diagram [12]. At last, the very recent publication covering a 25-year span [13] has reported a definite increasing trend for all chronic obstructive respiratory symptoms / diseases, as well as for airflow obstruction, with the highest increments shown by allergic rhinitis, usual phlegm, COPD, and airflow obstruction.

It is to note that the Italian Medicine Agency (AIFA) utilizes in its annual report on medicines use in Italy (Rapporto OSMED 2015) the prevalence rates for asthma (7.2\%) and COPD (3.1\%) derived from the Health Search data base of the Italian Society of General Practice. Such figures differ from those provided by Eurostat: $4.8 \%$ asthma, 5.1\% COPD.

The quoted CNR general population studies let us also provide information on medicines use as directly reported by interviewed people. Simoni et al. [14] showed the following frequencies of habitual and occasional drug use in the Po Delta area: 19.4 and 5.0\% in males, 32.0 and $6.1 \%$ in females. As a validation, the use of medicines used in the last 48 hours was quite similar between the CNR studies and the data provided by the National Health Service: 28.1 vs $26.3 \%$ in males, 40.1 vs 35.2 in females. When stratifying by disease category, medicines for broncho-pulmonary conditions had very low figures for habitual use (less than 5\%). The same Authors later analyzed the data of both the rural area of Po Delta and the urban area of Pisa [15]. They confirmed a low habitual use (5.2\%) for the broncho-pulmonary therapeutic group. Also, most people of the general population who reported presence of respiratory symptoms/diseases or impaired lung function did not use medicines. The underuse of medicines was lower in the urban than in the rural area.

The 2015 AIFA Report pointed out that the prevalence of the treatment with drugs for airways obstructive syndromes was $13 \%$ of the total enrolled population, with minor variations by gender and latitude, but increasing by age. AIFA uses for COPD five indicators calculating prescriptive appropriateness and adherence to prescribed treatment: - Percentage of patients with COPD admission in treatment with inhaled corticosteroids (ICS) (in 2015: $\mathrm{n}=54086$; 59.1\% of all admitted with COPD; variation vs previous year $=+3.5 \%)$ (Region 
with highest \%: Province of Bolzano, 69.5\%; region with lowest \%: Sicily, 48.5\%)

- Percentage of patients with COPD admission in treatment with long acting beta agonist (LABA) w/o long acting muscarinic antagonist (LAMA) (in 2015: $\mathrm{n}=54086 ; 58.3 \%$ of all admitted with COPD; variation $v s$ previous year $=+4.2 \%$ ) (region with highest \%: Lombardy, $65.9 \%$; region with lowest \%: Sicily, $43.7 \%$ )

- Percentage of patients in treatment with inhaled corticosteroids (ICS) without exacerbations (in 2015: $\mathrm{n}=1660219 ; 53.3 \%$ of all patients in ICS treatment; variation $v s$ previous year $=-1.9 \%$ ) (region with highest \%: Province of Bolzano, 71.6\%; region with lowest \%: Calabria, 37.2\%)

- Percentage of patients in treatment with drugs for airways obstructive syndromes adherent to the treatment (in 2015: $\mathrm{n}=1855184$; $13.8 \%$ of all patients in treatment with those drugs (37.1\% without occasional users); variation $v$ p previous year $=-0.2 \%(0.7 \%$ without occasional users) (region with highest \%: Piedmont, $23.3 \%$; regions with lowest \%: Abruzzo and Campania, 10.4\%)

- Percentage of patients in treatment with drugs for airways obstructive syndromes in occasional treatment (in 2015: $\mathrm{n}=1855184 ; 62.8 \%$ of all patients in treatment with those drugs; variation $v s$ previous year $=0.5 \%$ ) (region with highest \%: Abruzzo, 69.8\%; region with lowest \%: Piedmont, 54.5\%).

The analysis of such indicators highlights appropriateness and adherence levels to be improved for several therapeutic areas, with important variations by region, gender and age-group.

Thus, AIFA pinpoints the importance of achieving optimal appropriateness and adherence levels through the participation of all medical doctors and allied health professionals, patients and care-givers.

The recent CNR studies on assessment of recommendations (Rec)/ guidelines (GL) application in general practice have shown higher value of appropriateness according to new GOLD Rec (61.4\% vs 35.6\%) and a higher value of over-treatment according to old GOLD Rec $(52.8 \%$ vs 25.0\%) [16]. GPs' adherence to treatment in accordance with GOLD severity classification was higher in the most severe patients than in the mild ones.

Similar findings were shown for treatment appropriateness following ARIA GL: $57.2 \%$ in patients with only allergic rhinitis, $46.3 \%$ in those with combined allergic rhinitis and asthma [17]. Such average figures depended on disease severity, ranging from 48.5 and $23.1 \%$ in mild intermittent to 88.6 and $95.0 \%$ in moderate - severe persistent patients.

In conclusion, future epidemiological surveys, beside monitoring traditional indicators (mortality, morbidity, prevalence and incidence of symptoms / diseases) should also collect information on prescriptive appropriateness and adherence to prescribed treatment in general population samples in order to find determinants of insufficient treatment adherence and suggest ways to overcome it.

\section{Analysis of currently available inhalation drugs and personalized treatment in asthma}

\section{What is "personalized treatment" in asthma?}

Over the recent few years, much attention has been given to the so called "personalized therapy" in the management of many respiratory diseases, including asthma. There is no clear consensus on what this expression means, especially in terms of difference with "precision medicine". According to some Authors [18], personalized medicine is "the final outcome of a long process of examining a disease, starting at the population level and using various approaches and disciplines to characterize subsets on subsets of such patients, ending with the single patient". In this attempt, "personalized medicine" in asthma includes different approaches to the management of the single patient taking into account specific clinical and functional findings (such as types and level of symptoms, frequency of acute exacerbations, comorbidities, presence of persistent airway obstruction or small airways involvement) and also specific skills, attitudes and practical issues (such as adherence to the therapy, knowledge of the disease and patients expectations) which may be specific for each single patient in terms of management strategies. In contrast, "precision medicine" focuses more on the specific etiologic and pathologic background underlying the disease in each single patient which may require the identification of specific targets of treatment (e.g., allergen immunotherapy or omalizumab in IgE-induced allergic asthma, mepolizumab or reslizumab in non-allergic eosinophliic asthma, etc.) [19].

This concept has been already considered in the new GINA 2014 guidelines, where it is suggested to distinguish "population-level medication choice" from "patient-level medication choice" [20]. Indeed, asthma is now defined as a "heterogeneous disease" which includes different clinical and biologic phenotypes, with the common characteristics of typical respiratory symptoms, large variability in airway obstruction, and of being sustained by a chronic inflammatory process of the airways. Different phenotypes have been described, particularly distinguishing "type-2 asthma" with an important eosinophilic inflammation which may be easily detected in blood or sputum samples, from "non type-2 asthma", where a neutrophilic or pauci-granulocitic pattern of inflammation may be observed in the airways [21]. These two different patterns of chronic airway inflammation are well known, and there are several demonstrations that they tend to remain fairly stable over time [22,23]. There is also a different response to treatment, with non-eosinophilic pattern showing a poorer response to inhaled and systemic corticosteroids.

Other important factors not strictly related to the biologic basis of the disease, such as patient preference and practical issues (ability to use medication, adherence, cost of treatments) may more often require to consider different treatment options for the single patient.

\section{Poor control of asthma and therapeutic options}

Despite the large diffusion of guidelines for asthma management, recent data demonstrate that the level of asthma control is still poor. Several real-life observational studies published in the last 15 years report an adherence rate ranging from 14 to $50 \%$ of the asthmatic subjects examined. An internet-based asthma survey showed that in Italy the proportion of patients reporting a poor asthma symptom control was higher than 50\% [24], and this proportion remained substantially unchanged in a 4-years follow-up period [25]. The reasons for this poor adherence are manifold. In front of an unintentional poor adherence (due to forgetfulness, confusion, cost of medications), intentional low adherence (due to unperceived need, fear of side-effects, or cultural issues) is probably more relevant, because it is related to the perception of the disease and to the expectations of the patient from the treatment. In particular, patients tend to stop asthma treatment when the level of symptom control has been reached and maintained over a period of time, in the assumption that asthma is not a persistent disease requiring regular treatment. This concept is difficult to be changed, and despite education and empathic discussion with the patient, the majority of patients intentionally stop drug use when they do not have symptoms.

This is the reason why different strategies should be considered for each single patient in order to satisfy the willingness of the patient to self-manage his/her disease and the need to maintain an adequate level of treatment. 


\section{"Flexible" therapy for mild to moderate asthmatic patients}

Patients with mild to moderate asthma are now defined as patients in whom a good control may be reached with step 1 to step 3 level of treatment, according to GINA guidelines [20]. In these patients who tend to self-reduce the level of asthma symptoms or to withdraw drugs when there are no symptoms, a more "flexible" approach to the asthma management may be suggested, in order to partially comply with the patients' expectation, without the risk of a loss in asthma control. Furthermore, the level of activity of the disease is also variable over time, in relationship with the multiple environmental triggers of asthma.

\section{As needed treatment}

Some studies tried to assess if treatment with inhaled ICS or LABA/SABA (short acting beta agonist) +ICS combinations, used only when symptoms appear, might be an acceptable option in alternative to regular treatment with low dose ICS in mild asthmatics. The BEST study compared the rescue use of salbutamol/budesonide (BDP) inhalation with the regular use of regular low dose BDP or rescue salbutamol alone [26]. Rescue salbutamol/BDP treatment was as effective as regular low dose BDP in inducing a 50\% reduction of the moderate exacerbations rate in comparison with salbutamol rescue medication alone; in addition, rescue salbutamol/BDP was associated with a $75 \%$ reduction in the total dose of ICS administered during all the study period, in comparison with regular low BDP use. This observation however was not confirmed in a similar pediatric population [27] and in another population with more severe asthma [28]. New randomized controlled trials are currently in progress, with the aim of definitely confirm the potential usefulness of rescue ICS/LABA combination use in these mild asthmatics [29].

\section{Maintenance and reliever therapy (MART strategy)}

In moderate-severe patients, low adherence may be associated with higher risk of moderate-severe asthma exacerbations. The attitude to reduce or stop regular treatment is frequently observed in these patients as well, mainly in relationship with the poor knowledge of the disease and the willingness of self-management. For this reason, the so-called "maintenance and reliever therapy" (MART strategy) has been developed, in order to gain an acceptable compromise between the willingness of the patient to have the lowest possible treatment for asthma and the efficacy in preventing moderate-severe asthma exacerbations. Acute asthma related events are associated with a greater decline in FEV1 in mild recent-diagnosed asthmatic patients, and in these patients ICS use has been shown to reduce the rate of FEV1 decline [30]. Several studies have largely demonstrated that budesonide (BDP) formoterol combination -reviewed in [31]. as low dose maintenance treatment and also as rescue medication in the presence of symptoms, were able to significantly reduce the rate of moderate-severe asthma exacerbations in comparison with other alternative strategies including regular use of ICS or ICS/LABA combinations [32]. This approach was possible for the rapid-onset action of the bronchodilation obtained with formoterol, which is not much different from salbutamol under this specific respect. The important effect of this strategy on the rate of asthma exacerbations may be explained by the time course of symptoms and rescue medication use in the few 4-5 days before the occurrence of a moderate-severe asthma exacerbation requiring oral corticosteroids [33]; the increase in the ICS dose during these days due to the rescue use of the ICS/formoterol combination may explain the reduction of moderate-severe exacerbations. In addition, this strategy is associated with a reduction of the mean dose of ICS administered during the stable phase of the disease (this point is appreciated by the patient who wont to use the minimally effective dose of drug) and with a high acceptance by the patient who want to selfmanage their disease.

Obviously, both the aforementioned strategies require that the patient is a good perceiver of asthma symptoms, in order to "catch" the minimal changes in symptoms frequency and severity, and then to use properly the rescue doses of the drugs, leading to a rapid resolution of the impending exacerbation.

\section{Tailoring therapy in asthma}

Personalized medicine (more specifically precision medicine) may regard some specific asthma pheno-endotypes, which may require an intervention on the specific mechanism of the disease in each individual patient (Table 1).

Allergic asthma is a well-known pheno-endotype: it frequently starts in early age, is associated with type-2 pattern of airway inflammation (characterized by blood and/or sputum eosinophilia) and is associated in general with a good prognosis, although a minority of these patients may reach a high level of asthma severity which may be uncontrolled by the usual inhaled drugs. In these patients, allergen-immunotherapy may be a new option, considering that a recent study has demonstrated the efficacy of two dose regimen of well standardized allergen extracts of house dust mite on the prevention of asthma exacerbations induced by a progressive reduction in the ICS dose [34]. Similarly, in severe allergic asthmatics with pre-specified levels of serum IgE and sensitization to perennial allergens, the monoclonal antibody omalizumab is strongly recommended, due to the high efficacy in improving asthma control and reducing the frequency of asthma exacerbations [35].

Non-eosinophilic allergic asthma is another pheno-endotype which may potentially require a specific therapeutic approach. It is well known that in some patients, mainly affected by mild-moderate asthma, the airway pathology is sustained by a low Th2-expression inflammatory pattern (with neutrophils being often the predominant inflammatory cells), which may be less sensitive to corticosteroids. Steroid-naive symptomatic asthmatic patients with low sputum eosinophil percentage $(<3 \%)$ had a very high negative predicting value for improving FEV1 or bronchial hyperresponsiveness after a onemonth treatment with ICS [36]. At this time, there is no study showing that bronchodilators only may be used in this subgroup of noneosinophilic asthmatic patients, and further well-performed clinical trials would be recommended [37]. In a limited number of observations, the response to tiotropium in moderate-severe asthmatics was related to the percentage of neutrophil but not to eosinophil concentration in the induced sputum [38].

Recently, new biologic drugs with a specific target on some crucial points of the Th2-driven inflammatory cascade have been developed. Mepolizumab, Reslizumab and Benralizumab are different anti-IL5 monoclonal antibodies which have been demonstrated particularly effective on severe eosinophilic asthma. Several studies have shown that

Table 1. Tailoring therapy in asthma.

\section{Allergic asthma}

Anti-IgE (omalizumab)

Allergen - Immunotherapy (AIT)

Non-eosinophilic asthma

Poor response to ICS

Bronchodilators only?

Severe high Th2 expression asthma

Potential targets: IL-5, IL4/IL13, etc.

New biologics 
in uncontrolled patients with blood eosinophilia, these drugs may determine a more than $50 \%$ reduction in the rate of moderate-severe asthma exacerbations, with associated significant improvement in pulmonary function and quality of life [39]. Other biologic drugs with a specific target on different cytokines, (such as IL4/IL13) with a more "central role" in the Th2 cascade (Lebrikizumab, Dupilumab, Tralokinumab), are in progress, and may represent an important alternative in this subgroup of severe asthmatics selected according to different biomarkers (like serum periostin or exhaled nitric oxide) [49].

\section{Conclusions}

The aim of asthma management is still to obtain the control of symptoms and the reduction in the future risk [20]. To this end, it is important to consider the characteristics of each single patient, not only in terms of a potential specific pheno-entotype but also in terms of particular attitudes, expectations and adherence of the patient. Therefore, each physician needs to find the best strategy for each single patient.

The inhaled drug currently available (ICS, ICS/LABA ad LAMA) may allow to choose the best strategy among the different available options (regular treatment, occasional treatment, MART strategy, etc.), in order to improve compliance and self-management, reducing the drug burden and then "tailoring" the approach to the management of asthma.

Specific molecular targets for intervention are represented by allergic asthma, where allergen immunotherapy (in mild asthmatics) and anti-IgE monoclonal antibodies (in severe asthmatics) may represent important specific options, and severe eosinophilic allergic asthma, where the new currently available anti-IL5 monoclonal antibodies represent an important therapeutic resource in this small group of uncontrolled patients.

In the future, the personalized therapy will be increasingly more important in the management of asthma, both using the inhaled drugs that are currently available, but also using the old and new biologic drugs with specific biomolecular targets.

\section{Cost/benefit evaluation of different treatment approaches}

Asthma is a common complex chronic airways disease, with a significant burden for the society and for patients' quality of life. Indeed, asthma is considered to be one of the major health problems in the Western world [41]. Patients with asthma can have both short-term treatment for asthma exacerbations and long-term treatment to obtain and maintain asthma control [42]. The decision to start regular treatment depends on the severity of asthma at the time of diagnosis, and on the frequency and severity of exacerbations. A progressive, stepwise approach to drug therapy is recommended, with selection of the best options for the individual patient based on disease severity [41].

The concurrent treatment of asthma and its co-morbidities increases the direct costs of treatment. However, the lack of asthma control associated with deficient treatment leads to frequent emergency visits and hospital admissions, mainly in elderly people, and increases total costs of asthma management [42].

Although asthma is usually recognized as a costly illness, the total costs to society (direct, indirect and intangible asthma costs) are difficult to estimate, mainly due to different disease definitions and characterizations, but also to the use of different methodologies to assess the asthma socioeconomic impact in different societies. The asthma costs are very variables from country to country, however, according to recent analysis, it has been estimated that a mean cost per patient per year, including all asthmatics in Europe is $\$ 1900$, which seems lower than USA, estimated mean $\$ 3100$ [42]. The socioeconomic burden of asthma is substantial in Europe and is strongly associated with disease severity and diminished quality of life [43]. According to a study carried out in Italy [44], the average annual cost of drug treatment for an adult patient suffering from asthma is about $€ 1434$.

Due to the importance of this disease, expenditure on its treatment and the current need to keep public health care expenditure in check, it is necessary to investigate the prescription of antiasthmatic drugs in terms of appropriateness and sustainability of expenditure using the real population of local health care units. In recent years, researchers have pointed to the persistence of problems connected with drug use, such as choosing the wrong medication, incorrect duration of treatment, inadequate dosage regimens, and undertreatment $[45,46]$. For this reason, an analysis was also carried out on the appropriateness of prescribing for asthmatic patients by general practitioners in a local health care unit, Milano 2 local health care unit [1]. Based on this analysis, it has been suggested implementation of better health care planning and more appropriate prescription practices aimed at optimizing use of health care resources for the treatment of bronchial asthma. The results of the study should be extended to other regional/national reference local health care units, in order to define and compare average standard costs per disease and consolidated through the wide sample considered.

In the context of reduction and optimization of national health care expenditure has been developed tools for monitoring health care and drug expenditure, with the aim of controlling expenditure and assessing the achievement of targets in national and regional health care planning. The local/regional health service units currently have the following digital databases: personal detail databases, pharmaceutical databases, hospital illness databases. These sources and their integration are a powerful tool supporting conventional methods used in epidemiological studies [47]. Administrative databases offer low-cost information and, unlike other systems used for monitoring and assessment of quality of care, they do not require additional investment in terms of resources. Data contained in administrative databases are a by-product of economic and administrative operations, so characterize patients as "consumers" of health care system services. Assessment of drug utilization using databases enables us to determine consumption and prescription terms for an important sample of the asthmatic population, to define total and per capita costs for the disease and to suggest policies aimed at implementing expenditure appropriateness and optimization by detecting benchmarks between districts, physicians, different time periods, consumption by age and gender, and geographic distribution of the disease. However, it is important to highlight that use of administrative databases has some limitations. The main limitation of administrative databases is indeed the lack of clinical data; because they are created for accounting purposes, they omit important information on, e.g., patient lifestyle, symptoms, diagnoses, and intermediate outcome indicators.

Being able to measure and understand the concept of appropriateness of therapy and drug utilization are not only critical to determining the effectiveness and safety of a certain drug, but they are also important for the creation of programs aimed at improving the quality of drug use. The appropriateness indicator that was chosen in the analysis was the number of packs used, because the data sheets for antiasthma products as well as the relevant guidelines, recommend following a daily dosing regimen in order to achieve and maintain asthma control [41].

In order to assess prescribing medications, indicators of appropriateness were 1-3 packs per year (underdosed, inappropriate), 4-12 packs per year (presumably appropriate), and 13 packs per year 
(overtreatment, inappropriate). Indeed, prescription of over 12 packs per year by the physician may expose the patient to side effects due to overdosing, with a consequent waste of health care resources. The use of fewer than four packs per year is also to be considered inappropriate, because drug treatment must be constant in order to achieve control of the disease and avoid exacerbations.

Appropriate drug prescribing is of critical importance in order to achieve therapeutic objectives and to optimize the use of resources in modern health care systems. Adherence to antiasthmatic therapy is another key aspect. Indeed, adherence is one of the pillars of the patient's health management in the control and prevention of progression of the disease. Adherence can be assessed using the medication possession ratio indicator (MPR), that is the sum of the days' supply for all fills of a given drug in a particular time period, divided by the number of days in the time period, a patient is deemed to be adherent when their MPR is $80 \%$ [48].

Poor adherence to inhaled corticosteroid therapy is recognized as contributing to failure of treatment, with a consequent increase in morbidity, mortality, and consumption of health care resources [1]. In view of the importance of continuing drug therapy, especially in chronic diseases such as asthma, it is important to quantify the number of patients who are genuinely persistent in taking their medications. When taking of medication deviates from the prescribed regimen, situation-specific changes in the risk/benefit ratio can arise, with a decreased benefit, an increased risk, or both [6]. A number of studies have demonstrated that inadequate adherence (how far the patient follows the prescribed regimen of doses and administration intervals) and persistence (duration of time between beginning and discontinuing therapy) results in increased morbidity and mortality for a wide variety of diseases, and at the same time, significantly increases costs related to health management.

If asthma treatment costs increase, the availability of tools able to compare data on the use of health care interventions in terms of incremental cost per increment in efficacy clearly become of great importance. It is also necessary to transform such tools in a constant point of reference for the physicians and the health care policy makers choices. Appropriate drug prescription and good adherence with the therapy are of critical importance in order to achieve therapeutic objectives and to optimize the use of resources in modern health care systems.

\section{Inhaler devices: A key role in the asthma personalized action plan}

The prevalence of asthma has increased over the past decades and it is expected to grow further all over the world. Once diagnosis of asthma has been made, a successful asthma management aims to control respiratory symptoms and exacerbations, most of the time through an ad hoc inhaler device therapy when needed.

In clinical practice, patient's involvement by respiratory physicians has become crucial to improve asthma treatment. It helps patients to become aware of their disease and it reduces exposure to environmental trigger factors and comorbid conditions that contribute to asthma severity. On the other hand, self-reported symptom control such as daily PEF monitoring and quality of life questionnaires helps clinicians to estimate asthma severity more accurately. It is indeed common to misunderstand "asthma severity" with "uncontrolled asthma". Asthma severity is based on the level of treatment needed to control respiratory symptoms, it is evaluated retrospectively and over a long period, whereas asthma could be poorly controlled by incorrect inhaler technique and/or poor compliance to treatment.

\section{Inhaler devices for asthma}

Over the past few years it has been recognized the high prevalence of patients with poorly controlled asthma [49]. Once clinicians have decided to start patients on new inhaler therapy, three steps should be taken into account: drug choice, inhaler device choice and patient training in use of inhaler. Any inhaler device requires a correct inhaler technique in order for the drug to be delivered properly to the lungs and to be effective. By contrast inhaler mishandling compromise bronchodilatation and/or anti-inflammatory action on the bronchial tree leading to uncontrolled respiratory symptoms and increased exacerbation risk [50]. Three main types of inhaler devices are available, the pressurized metered dose inhaler (MDI), the dry powder inhaler (DPI), and the soft mist inhaler (SMI). MDI was introduced in the 1950s and consist of a pressurized canister, a metering valve and stem, and a mouthpiece actuator. It requires that the patient exhales completely before inhaling the medication, actuates a coordination between simultaneous inhalation and device activation immediately after, that inspires slowly and continuously during inhalation and finally holds breath for at least $10 \mathrm{~s}$ [51]. An incorrect procedure could deposit the drug in upper airways causing side effects in the mouth and the oropharynx. Patients who experience coordination problems often are asked to use an additional spacer device which most of the times results in patients lack of compliance because it is cumbersome.-DPIs were introduced in the 1980 s to exceed these limits: coordination is not needed and inhalation should be fast and start immediately. However, DPIs have different internal resistance and a flow-dependent dose emission. The turbulent flow depends on the speed of the inhalation maneuver. There is a minimum threshold energy required to produce particles with appropriate size able to reach the bronchial tree. Inspiratory flow rates of 30 to $60 \mathrm{~L} / \mathrm{min}$ are required to disaggregate and aerosolize the drug when using a DPI device [52]. Some studies have highlighted that young children and patients with severe airway obstruction have experienced problems using a fast inhalation flow. Airflow obstruction increases the need for inhaled bronchodilator therapy, but can decrease the effectiveness of that treatment. In these cases, to improve aerosol delivery into the lungs, the patient should be encouraged to use a slow breathing pattern with a normal tidal volume and an occasional deep breath using alternative devices [53]. In patients affected from severe asthma not well controlled by high dose inhaled glucocorticoids plus a long-acting beta agonist, it has been shown that tiotropium could be beneficial [54]. The Respimat SMI is an alternative to MDIs that forces a drug solution through a series of channels leading to two nozzles that focus two fluid jets into a precisely calculated convergence producing a vapor of inhalable droplets. SMIs release the medication in a soft mist, which lasts in the air about six times longer than the aerosol from an MDI. The lower velocity of the aerosol decreases oropharyngeal deposition. The longer duration of the aerosol cloud increases the window for successful inhalation, thus reducing problems with co-ordination between actuation and inhalation [55].

\section{Patient education in inhaler use and compliance to treatment}

Optimizing inhaler use for each individual asthma patient is therefore a key point that should be highlighted in clinical practice to improve compliance to treatment. Patients should be trained by experienced people, doctors and nurses should spend enough time to offer simple and clear instructions. When patients are admitted to hospitals there is usually plenty of time for doctors and nurses to experience different devices, to teach patient the inhalation technique and to evaluate it. Conversely, during follow up visits in clinics it could be the case that this procedure may be seen as time-consuming and provision of 
written materials such as patient information leaflets or multimedia methods such as video demonstrations, touch-screen computer or webbased teaching, could be helpful. There are only few studies so far looking at the effectiveness of inhaler training. In one small study the best results were achieved when verbal and written instructions were provided at the same time [56]. However, any training system should address different patient education levels, not everyone is able or willing to read written information or multi-media or touch-screen computers. Overall, face-to-face demonstration seems to be the most effective way to train patients. It is worth noting that increasing awareness of the importance of correct maneuvers is a crucial step towards improving asthma control because patient education has been shown to improve compliance to treatment [57].

After being trained patient should be enough motivate to both maintain proper inhaler technique and to continue on treatment. Some studies observed that repeated instructions in inhaler technique improve adherence to therapy and asthma outcome [58]. In real life patients make several errors with inhalation device, so it is also worth assessing inhaler technique in different occasions. It could be useful therefore asking General Pratictioners (GPs) and pharmacists to contribute to motivate and supervise patients from time to time to give a valid feed-back to clinicians. Armur et al. demonstrated that a Pharmacy Asthma Care Program improved outocomes for patients in the community [59].

\section{Conclusions}

Evidence from systematic reviews and meta-analyses suggests equivalence among nebulizers, MDIs, and DPIs for delivery of bronchodilators and glucocorticoids when used correctly [60]. Thus, the selection of an aerosol delivery device is usually based upon the preference and convenience of the clinician and patient, the ability of the patient to use the device correctly rather than a clear superiority of one device over another [61]. Choosing the appropriate inhaler device, training the patient in inhaler use and providing patient education is challenging and is meant to be a shared responsibility among physicians, respiratory therapists, nurses and pharmacists. Devices able to analyze spontaneous inhalation profiles and to provide feedback about inhalation rate could help clinicians in choosing the optimal inhaler, but more knowledge is needed to improve these fields [62]. Patient education and involvement is essential to create a partnership between health care professionals participating in clinical care and patients because it represents one of the keystones of successful asthma management. Despite national and international guidelines there is still little evidence on the best strategies for implementing recommendations and there is a need for additional studies about patients personalized asthma action plan [63].

\section{Adherence to asthma treatment: Myth and reality}

"DRUGS DON'T WORK in patients who don't take them."

"There are all kinds of things you can do to marry literacy with health." C. Everett Koop

A recent publication of the European Respiratory Society has pointed out that asthma is a highly prevalent disorder of the airways that affects people of all ages in all European countries as well. In whole Europe about thirty million people - children and adults under 45 years of age - suffer from this disease [64]. Asthma has a relatively low fatality rate compared to other chronic diseases. According to the latest WHO estimates, released in December 2016, there were globally 383,000 deaths due to asthma in 2015 [65].
Most asthmatic patients, however, can be managed successfully in primary care according to widely accepted guidelines [66,67]. A bulk of large, randomized clinical trials have found that, apart from a relatively small proportion of patients with "difficult asthma" requiring specialist referral and supervision, the disease may be totally or well controlled by trigger avoidance and inhaled medications $[68,69]$. Conflicting with this possibility, and despite the current asthma guidelines stress the importance of assessing and enhancing adherence to asthma treatment, medication adherence rates in individuals with asthma are consistently low in practice $[66,67]$.

\section{Adherence and nonadherence to asthma treatment}

The benefits of drug therapy for asthma have been well established. The main goals of adult asthma management are i) to achieve and maintain control of symptoms, and ii) to prevent or attenuate asthma exacerbations. In a relevant proportion of patients, it is also possible to improve and maintain pulmonary function and achieve an acceptable level of physical activity; to avoid the progression towards irreversible airflow obstruction, and to prevent deaths from asthma. There is currently no cure for most types of asthma, and achievement and maintenance of these goals may depend on appropriate patient education and adoption of flexible self-management programs. Over the past few decades we have witnessed several phases in the development of approaches aimed at ensuring that patients continue therapy for chronic conditions for long periods of time. Initially the patient was thought to be the source of the "problem of poor compliance". Later, not only the term "compliance" has mostly been superseded by the term "adherence", which acknowledges the patient's rights to choose to take the prescribed medication or to follow other healthcare-related advice, and eliminates the concept of blame if this does not occur [70,71]. In addition, the role of the providers and other stakeholders was also addressed. Now we acknowledge the complexity of nonadherence to asthma treatment and we are aware that a systematic approach is required. The idea of compliance is associated too closely with blame, be it of providers or patients; thus, the concept of adherence seems a better way of capturing the dynamic and complex changes required by many players over long periods of time to maintain optimal health in people with chronic diseases.

Failure to adhere to a regular management plan for asthma (including the regular taking of preventive therapies) results in poor asthma control which has clinical consequences, such as symptoms and exacerbation of asthma, and decreased quality of life for the patients, as well as economic consequences, such as emergency department visits and increased hospitalization, resulting in health care redundancy and unnecessary high costs.

Despite nonadherence to prescribed medications is a widely perceived phenomenon, it continues to be a frequent and underscored problem in patients with asthma even in recent years. The causes for nonadherence are many, including physical, psychological, cognitive, sociocultural, and economic issues. There are numerous reasons why patients do not take their medications properly. For example, some find the cost of the medications unaffordable while others skip their doses because they are afraid of possible side effects, and of course some others are just plain forgetful. In addition, due to the intra-individual variability of their disease, patients are prone to be confused by the erratic presentation of symptoms. However, better education and automated reminders can help improve adherence.

Objective measurement of adherence should be implemented whenever possible. Review of pharmacy refill data or electronic monitoring of inhaler actuation may be a preferred method to assess adherence. Educational programs should be specifically designed to address the unmet needs and specific reasons for nonadherence for the target population. 
The participants at the WHO Adherence meeting held in June 2001 concluded that defining adherence as "the extent to which the patient follows medical instructions" was a helpful starting point [72]. Subsequently, the issue of adherence to long-term therapies in a number of chronic diseases states including hypertension, diabetes, smoking cessation, and asthma has been thoroughly addressed by the WHO [73]. Although most research has focused on adherence to medication, adherence also encompasses numerous health-related behaviors that extend beyond taking prescribed pharmaceutical agents [74].

Nonadherence to treatment is a common problem that can threaten patients' health individually as well as add huge costs to the health care economics and challenge the efficiency of public health system. In operational terms, the variables of adherence are defined as: "not filling a prescription", "not taking medication", "errors in dosage intervals", "reducing doses", "taking extra doses" and "taking additional nonprescribed medication". Surprisingly, nonadherence is also common among patients with difficult asthma. In an interview-based investigation, it was found that $35 \%$ of patients with difficult-to-treat asthma, who had been referred to specialized centers for assessment, had filled less than $50 \%$ of prescriptions for inhaled fixed-dose combination therapy, with $88 \%$ of them admitting poor adherence after initial denial [64]. Whereas the types of nonadherence varies from the most frequent 'dose missing' to the less common 'not refill in time' and 'stop taking drugs', adherence is a complex and multifaceted phenomenon that may be influenced by a number of factors.

The failure of asthmatic patients to adhere to physician-prescribed regimens, either pharmacologic or behavioral, has been well documented in medical literature $[75,76]$. Poor adherence to asthma medication regimens has been repeatedly demonstrated in both children and adults, with rates of nonadherence commonly reported from 30 to $70 \%$ [70]. Medication regimens for asthma care are particularly vulnerable to adherence problems because of their duration, the use of multiple medications, and the periods of symptom remission. The clinical effects of this nonadherence by asthmatic patients can include treatment failure, unnecessary and dangerous intensification of therapy, and costly diagnostic procedures, complications, and hospitalizations. Inhaler competence, the skill to inhale correctly, is particularly relevant for asthma medication, as inhaling of drugs requires considerable skill and practice [77]. Even if medication is taken daily, deposition in the lungs will be low with incorrect inhalation technique. Although the measurement of adherence is an important component of both medical and behavioral interventions to control asthma, relatively little research has directly addressed the reliability and validity of the measures most widely used to assess asthma medication compliance. Common measures used to assess adherence to asthma medications include direct measures, which confirm the use of medication by assaying it in blood, urine, or saliva, or which confirm the ability to use a medication, such as observed skill in using a metered dose inhaler or dry powder inhaler. Indirect measures infer use with varying degrees of reliability, by use of clinical judgment, self-report/asthma diaries, medication measurement, and electronic medication monitors. There are, obviously, limitations in using these measures due to their low sensitivity and specificity, but their discussion is beyond the purpose of this review.

\section{Understand and solve the problem of nonadherence}

Poor adherence to treatment regimens has long been recognized as a substantial roadblock to achieving better outcomes for chronically diseased patients. In general, factors related to or involved in adherence to medications are related to five domains: i) patient-related, ii) disease-related, iii) therapy-related, iv) health system-related, and v) social/cost-related. Regression modeling, a statistical technique that assesses the independent strength of the relationship between two variables while holding other factors constant, identified the six key predictors of medication adherence. In order of importance, these include:

1. Patients' personal connection with pharmacist and pharmacy staff

2. Patients' level of information about their health status

3. Patients' affordance of prescribed medications

4. Patients' perception of importance to take medications exactly as prescribed

5. Patients' level of continuity in health care

6 . The extent to which medications may cause adverse side effects.

These predictors point out a variety of routes by which both doctors and pharmacists can address better health outcomes by informing patients and their caregivers of the importance of treatment adherence.

Intuitively, the systematic assessment of adherence is of cornerstone importance, and efforts should be made to ensuring it in as larger as possible number of asthmatic patients. However, one must take into account that a number of other factors including inhaler handling, the persistence of asthma triggers, and the presence of comorbidities in patients that are unable to reach an optimal or good control of their asthma should also be addressed by physicians and pharmacists pro-actively. Hence, the patient should not only understand the concept of inhaled therapy for asthma control, but also be aware that poor inhalation technique may be a straightforward determinant of failure of asthma therapy. Patients with poor or incorrect inhalation technique must be re-trained by means of direct tuition or freely available videos in the website. Furthermore, the persistence of asthma triggers is a common feature of uncontrolled asthma. Thus, efforts should be made to identify persistent sources (often perennial, domestic and/or occupational) of sensitizing allergens and nonspecific respiratory irritants including cigarette smoking. A short checklist of key questions for the assessment of adherence and persistent asthma triggers is reported in Table 2.

A recent systematic literature search and meta-analysis has shown that despite heterogeneity among studies in terms of definitions of adherence and asthma exacerbations, the majority of the high-quality

Table 2. Checklist for the assessment of adherence and persistent asthma triggers in patients with poor controlled asthma.

Does the patient know what asthma and asthma control are?

Is the patient aware of the concept of inhaled therapy for asthma control?

Is the patient using the appropriate inhaled therapy according to the stage of his/her asthma?

Does the patient take inhaled therapy regularly?

Does the patient handle his/her inhalers correctly?

Does the patient know his/her sensitizing allergens and does he/she avoid exposure?

Does the patient avoid exposure to active/passive smoking and other irritants?

Does the patient avoid the use of detrimental medications? 
studies consistently reported an association between low adherence and higher risk of severe asthma exacerbations, both in adults and children [78].

Another systematic review evaluated interventions to improve adherence to treatment with inhaled corticosteroids in asthmatic patients by using components of the chronic care model [65]. This study included two groups; in the first group, the choice of treatment was actively shared and negotiated between the patient and the physician; in the second group, the physician alone selected the treatment regimen. The results showed that the shared-decision making strategy was associated with a significant improvement in adherence to inhaled corticosteroids compared to the physician only decision-making strategy [79].

\section{Health literacy}

Medications play a prominent role in the treatment and control of asthma, and thus failing to adhere to prescribed medication regimens contributes to an array of poor health and staggering economic burden. Current evidence from studies in children and adults suggests that inadequate health literacy is an important key barrier to asthma knowledge $[80,81]$. Hence, focusing on nonadherence related to health literacy in asthmatic patients may yield benefits in term of both human suffering and economic costs.

Literacy refers to an array of intellectual skills and capabilities, including reading, writing, understanding, speech and speech comprehension, and basic math's calculations. Health literacy, instead, refers to how well one applies this broad range of capabilities in the context of health care. Health literacy has been defined as "the degree to which individuals have the capacity to obtain, process, and understand basic health information and services needed to make appropriate health decisions" [82].

Insufficient health literacy of asthma has been associated with lower adherence to treatment and worse metered-dose inhaler technique. A number of studies investigating patients' adherence to asthma medications reviewed by Rosas-Salazar and coworkers, have linked inadequate asthma literacy with poor health outcomes [83].

According to a systematic review by the Cochrane Airways Group, training patients in self-management of asthma, based on self-monitoring of both peak expiratory flow and symptoms coupled with a written action plan and regular medical review, appeared to improve health outcomes for adults with asthma. In addition, education on selfmanagement reduced hospitalizations, unscheduled visits to the doctor, days off work or school and nocturnal asthma. Improvements in lung function were also achieved [84]. The Cochrane review also showed that incomplete approaches such as the use of limited education (information only) about asthma do not appear to improve health outcomes in adults with asthma although perceived symptoms may improve. A "proof of concept trial" found that three 30-minute sessions of motivational interviewing of asthmatic patients with poor adherence within a 6 week-period improved inhaled corticosteroid refills and the asthma control test compared to usual care [85].

\section{Conclusions}

The global burden of asthma, a chronic, inflammatory disease of the airways, is considerable. Its effects include reduced quality of life, lost productivity, missed school days, increased health-care costs, the risk of hospitalization and even death. As a rule, medications are used to treat, cure, and prevent illnesses and their consequences. Although effective treatments that have been shown to dramatically reduce asthma morbidity are available, they are effective only when properly used by patients. Thus, they play a prominent role in the treatment of asthma and other chronic diseases as well. Failing to adhere to prescribed therapeutic schedules contributes to an array of poor health outcomes in asthmatic patients. Because human behavior is the necessary interface between good therapies and therapeutic effectiveness, both clinical researchers and clinicians should be aware of the myriad of factors associated with patient adherence. There are numerous reasons for which patients do not take their medications properly. For example, some find the cost of medications prohibitive while others skip their doses out to avoid side effects, and of course some are just plain forgetful of taking them. However, one should keep in mind that better education and automated reminders could help improve adherence to prescribed treatment of asthma (Table 3 ).

There is an urgent clinical need for systematic, proven methods to assess and address medication nonadherence in patients with asthma. Large, well designed clinical trials to investigate the efficacy of remote electronic monitoring and reminder systems to improve adherence are needed. Inadequate adherence and treatment discontinuation are intrinsic to the nature and variability of asthma and good adherence tends to be associated with lower risk of severe asthma exacerbations.

Poor health literacy has been identified as a major cause of medication non-adherence, and failing to adhere to prescribed medication regimens contributes to an array of poor health outcomes.

A comprehensive program of asthma care should include patients' tuition on the correct of inhalers and self-management plan. In addition, adherence should be routinely assessed in the real life by interviewing patients, and reviewing prescription and refill frequency. Adherence with controller medication should be encouraged even when symptoms are mild, infrequent, or absent. Finally, adherence to asthma treatment should be routinely addressed by using a non-judgemental approach within the context of a poor adherence before considering a step-up in the treatment of asthma.

The distance between myth and reality of adherence to prescribed medication is huge as yet. Despite the relationship between health literacy and the capacity to learn asthma self-management skills is unknown, the current evidence supports the concept that an improved knowledge of the disease may be beneficial in terms of adherence. Therefore, intervening at the interface between patients' health literacy and adherence to prescribed medications may be of strategic importance to overcame the nonadherence of asthmatic patients and its detrimental effects on their health and wellbeing.

Table 3. Questions to be asked to asthmatic patients to understand how they take asthma medications.

\begin{tabular}{l}
\hline Do you have difficulties in adhering to asthma therapy? \\
\hline Do you ever forget to take your asthma medicine? \\
\hline Are you careless about when you take your asthma medicine? \\
\hline Do you sometimes stop using your inhaler(s) when you feel better? \\
\hline Do you stop taking or skip your inhaler(s) if it seems to make you feel worse? \\
\hline Do you take inhaler(s) as rescue medications rather than regularly? \\
\hline Do you sometimes skip inhaler doses or skip an asthma medicine entirely because of the cost?
\end{tabular}




\section{Asthma: Toward a definition of the pillars of a correct therapeutic strategy}

Main goals of asthma management are: achieve good control of symptoms maintaining normal activity levels and to reduce the risk of future exacerbations and fixed airflow obstruction appearance minimizing medication side-effects [20].

The pillars of a correct therapeutic strategy can be summarized as follows: correct diagnosis, correct treatment, correct adherence to therapy, correct follow-up.

\section{Correct diagnosis}

Clinical and instrumental diagnosis is not always simple in asthma. However, three are the constant features helping in a correct diagnosis.

1) Bronchial hyperresponsiveness. In absence of bronchial hyperresponsiveness there is not asthma [86]. When anamnesis is suggestive for asthma and spirometry normal a bronchoprovocation test can be helpful in confirming the diagnosis [87].

2) Airflow obstruction with reversibility acutely or over time. A correct diagnosis of airway obstruction must be based on a spirometry with FEV1/FVC value below the lower limit of normal [88] to avoid misdiagnosis in adults and older patients. Misdiagnosis is possible when obstruction is considered for FEV1/FVC $<75-80 \%$ of the predicted value [87]. Secondly, reversibility of airway obstruction is a milestone in asthma diagnosis. Moreover, many COPD patients show changes in airway over 12\% FEV1 and $200 \mathrm{~mL}$ after short acting bronchodilator $[88,89]$. This occurs for many reasons as gas compression [90] or effect of increased bronchial wall thickness [89]. For these reasons "Asthma COPD overlap" is considered only when a bronchodilator response higher than $15 \%$ change and 400 $\mathrm{mL}$ of absolute value from baseline is present after bronchodilator $[90,91]$.

3) Airflow obstruction variability. Patterns of obstruction change over short time in patients [92], so monitoring of airflow obstruction during time can help diagnosis.

\section{Correct treatment}

Asthma treatment must be performed using a control-based asthma management cycle [93]. In control-based asthma management, pharmacological treatment is adjusted in a continuous cycle that involves assessment, treatment and review. Asthma outcomes have been shown to improve after the introduction of control-based guidelines for many patients in primary care. Reviewing symptom control, risks of exacerbation are reduced [94]. Different therapeutic steps are considered: from "as-needed" short acting beta agonist use to low and high dose inhaled corticosteroids with addition of long acting beta-2 agonists and antileukotriens. When severe asthma occurs (step 4-5) patients need continuous therapy with high doses of drugs (also with oral corticosteroids), Tiotropium and recent biological agents (omalizumab mepolizumab, etc.).

\section{Correct adherence to therapy}

Poor adherence is defined as the failure of treatment to be taken as agreed by the patient and the doctor. It is very common: $50 \%$ of adults and children do not take controller medications as prescribed. Poor adherence contributes to uncontrolled asthma symptoms, exacerbation risk and asthma-related death.

Optimal asthma control depends on the selected drug, the device that is employed and on the removal of factors that reduce patients' adher- ence to therapy $[95,96]$. Proper inhaler technique is an important component of effective asthma therapy and patients with evidence of poor adherence and asthma control should be targeted for a review of their inhaler technique [97-99].

\section{Correct follow-up}

Follow up consultations should take place at regular intervals. Regular review should assess asthma control considering patient's symptom control, exacerbation risk factors, flare-ups, comorbidities. Inhaler use must be assessed and corrected when necessary.

Follow-up can today utilize devices characterized by smart technology helping to monitor adherence. They accurately record the time when each dose was taken, store data over a reasonable time period, and provide access to adherence data. That's why "smart technology" would improve patient adherence, with possible positive impact on asthma control.

\section{Clinical and device preference comparisons of new versus old fixed-dose combination inhalers}

Asthma and chronic obstructive pulmonary disease (COPD) are progressive inflammatory respiratory diseases that affect millions of people worldwide [100,101]. Asthma is a serious global health problem with an estimated 300 million affected individuals, predicted to increase to 400 million by 2025 [102]. COPD is the fourth leading cause of death in the world and predicted to be the third by $2030[20,103]$. This disease is a major cause of chronic morbidity and mortality, with an estimated 4.5 million annual deaths attributable to COPD over the next 30 years [103].

The ability to identify poor disease control is a pre-requisite for improving asthma and COPD treatment and management. However, over the last decade, European studies have shown little apparent improvement in the levels of symptom control [104,105]. Asthma control in clinical practice is suboptimal despite available therapies (Figure 1) $[105,106]$. This lack of disease control results in high numbers of patients exacerbating (Figure 2). Many factors that contribute to suboptimal asthma and COPD control have been identified, including concomitant rhinitis, a common co-pathology, and smoking. Equally as important is appreciation of patients' views and concerns about maintenance therapy and the level of satisfaction with the prescribed inhaler device [107].

Practical barriers are also often encountered, such as poor inhaler technique. However, data from randomised controlled trials (RCT) suggests that there are no significant differences between inhaler types, and national and international guidelines base their recommendations for inhaler use on these data. Nevertheless, RCTs are generally representative of fewer than $5 \%$ of the population of patients with asthma [108]. often excluding typical cases seen in general practice including smokers, patients with comorbidities, and those that suffer from severe or unstable disease. Patients participating in RCTs are closely monitored to ensure correct use of inhaler therapy and usually require a minimal adherence rate for continued participation. This does not reflect the situation in the general patient population where adherence tends to be relatively low.

Real-world evidence corroborates and reinforces the results from clinical trials using data from multiple sources, including electronic health care records, claims and billing data, product and disease registries, and data collected through personal devices and health applications [109]. This facilitates the inclusion of a broad range of patients comparable to those typically examined in primary care settings. 
A study by Giraud et al., in patients using metered dose inhalers (MDI), reported that only $30 \%$ were able to perform the correct inhaler technique [110]. This highlights the importance of evaluating correct inhaler technique and providing the necessary training to all patients on inhaler use. More recently, Molimard et al. reported an association between device mishandling and an increase in observed COPD exacerbations [111].

A recent real-world study using the global inhaler technique initiative Helping Asthma in Real People (iHARP) database to identify serious inhaler handling errors found the most common errors to be failure to exhale before inhalation, insufficient breath-hold at the end of inhalation, and insufficiently forceful inhalation from the start [112]. The CRITIKAL study identified specific inhaler errors as critical errors in patients using both MDI and DPI, based on frequency and association with asthma symptom control and exacerbation rates [100].

Due to the heterogeneity and complexity of asthma and COPD, patients are often prescribed mixed inhaler regimes, such as DPIs for maintenance and pMDI for reliever therapy. These are liable to confuse patients due to the very different inhalation techniques needed to use them correctly. This can impact drug delivery to the target airways of

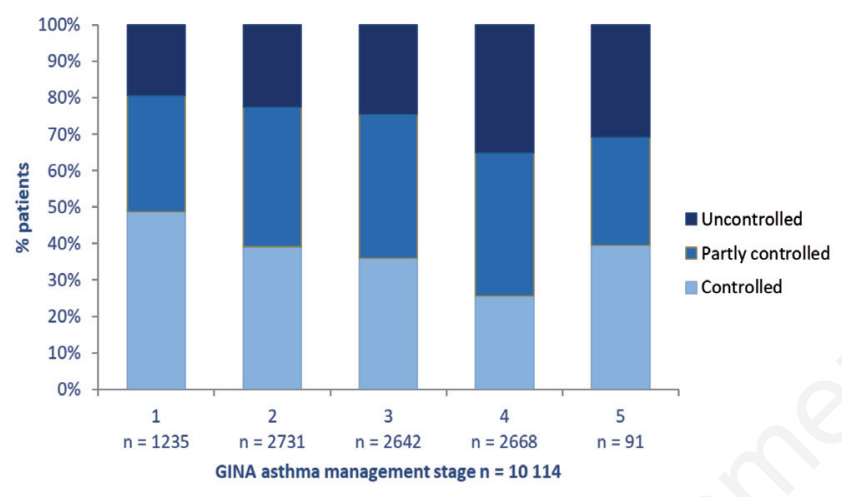

Figure 1. Current asthma control in the UK. $p<0.001$ (Chi-square) for differences in asthma control between BTS steps; asthma control defined using data from patient recorded questionnaires. GINA, Global Initiative for Asthma.

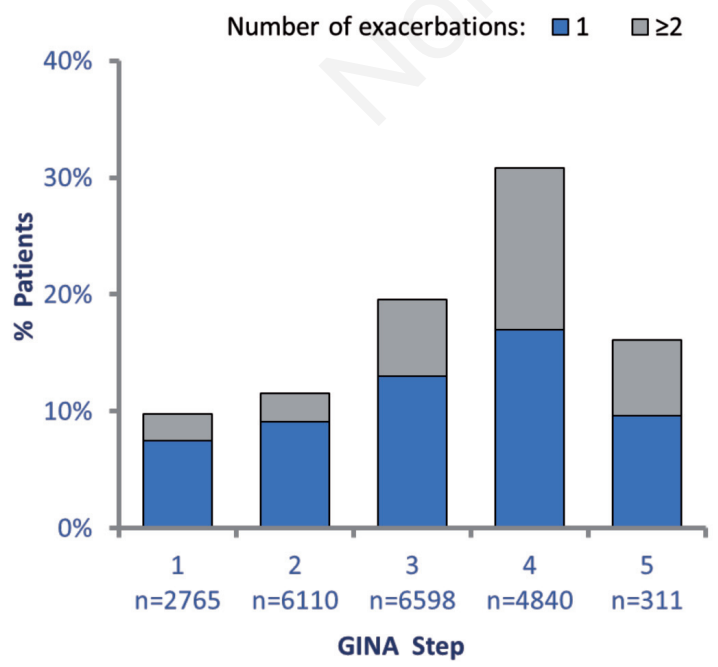

GINA: Global Initiative for Asthma

Figure 2. Exacerbation rates despite current therapy. the lung, and in turn effect exacerbations and disease control [113]. Maintaining device consistency and increasing the simplicity of the treatment regime will help decrease critical errors in inhaler use.

Next generation inhalers, that increase patient ease-of-use, have been developed to enhance the delivery of drugs to the bronchial tree and to improve the inhalation technique by reducing the possibility of making errors while operating the device. Inhaler devices such as the ELLIPTA $^{\circledR}$ and the NEXThaler ${ }^{\circledR}$ were both found to reduce critical errors compared to other MDI and DPI inhalers [114-117].

The CRITIKAL study identified multiple inhaler errors affecting asthma control outcomes [100]. One of the top recorded errors was actuation before inhalation [113]. To combat this error, breath actuated inhalers (BAI) have been developed. These inhalers were found to increase the odds of asthma control, and decrease severe exacerbation rates, for patients initiating or increasing ICS therapy [118]. Devices such as the K-Haler and Synchrobreathe have shown promising preliminary results with increasing lung deposition, efficacy and patient satisfaction.

Many of the newer devices are reported to be easier to use [114117]. However, it is still unknown what this means for both health care professionals (HCPs) and patients. Studies have shown that the nature and extent of training required to achieve and maintain device mastery varies with different devices [118]. With changes in inhaler technology, drug formulations have also evolved. The recent incorporation of airway-compatible lipid-based porous particles to keep drug crystals suspended in the propellant without needing additional excipients, has resulted in a highly uniform formulation. These formulations have shown minimal drug crystal-crystal interaction throughout manufacturing, storage, and drug delivery, and are stable over time, delivering consistent doses under a variety of storage or handling conditions. The effect of inhalation therapy is determined by multiple factors, including the amount of therapy reaching the lungs and its distribution throughout the airways [119]. Targeting inhaled drug formulations to the peripheral airways is not efficient, with most of the formulations being deposited in the central airways. Reducing the mean particle size of the inhaled drug increases the fraction reaching the peripheral areas of the lung [111]. Meta-analysis of RCTs demonstrated that extra-fine ICS have significantly higher odds of achieving asthma control with lower exacerbation rates at significantly lower doses than fine-particle ICS [120]. Real-world studies have shown that extrafine ICS reduce exacerbations and improve asthma control in patients starting with higher doses of extrafine-particle size ICS [121].

To further improve outcomes in patients with respiratory disease, treatment has progressed from monotherapy to combination therapy. Together with the above-discussed options available to improve asthma control, finding the perfect combination of easy to use inhaler and drug formulation can be difficult. Furthermore, not all inhaler/drug combinations are licensed for equal use worldwide

Many studies have investigated inhaler effectiveness for respiratory disease control. However, the results are conflicting with RCT data, suggesting DPI use was associated with higher rates of adherence in patients with asthma, whereas real-world studies find MDIs to be associated with better control, treatment stability, and lower exacerbation rates. For patients with COPD, soft mist inhalers, such as Respimat ${ }^{\circledR}$, were more accepted by patients than MDIs and DPIs [122]. A study by Bender et al. found that the top reason for non-adherent patients to become adherent was if they could feel more immediate effects of the treatment [123].

Is there are way for patients to identify and rectify their inhaler errors in real time? Technology, such as inhaler compliance assessment technology, an acoustic recording device attached to the inhaler able to measure and identify technique errors [124], as well as smartphone 
add-ons to monitor lung function and track flare-ups, have been developed. Recent research has shown patients that receive inhaler reminders are more adherent than those who did not [125].

Finding an optimal match between the patient and the inhaler device is an achievable goal. However, all the available data points to a need for an evidence based approach enabling the caregiver to make a prompt rational choice. Prospective experimental validation is needed to confirm the validity.

\section{Analysis of currently available inhalation drugs
in COPD}

Inhalation drugs represent for many years a mainstay in the treatment of COPD. The last recommendations GOLD it is mentioned and stressed both the role of short and long acting Beta2 drugs (SABAs and LABAs) and that of short acting and long acting antimuscarinic drugs (SAMAs and and LAMAs) in the management of COPD. Likewise, the same text underlines the role of combinations of SABAs and SAMAs, LABAs and LAMAs in various situations and illustrate as well the bronchodynamic effects, their action on the riduction of axacerbations, the improvement of Dyspnea indexes and that of the quality of life [126]. This last edition of GOLD (IBIDEM) marks also the positive role of the combinations of the inhaled steroids (ICS) and LABAs in improving lung functions, health status and in reducing exacerbations of moderate and severe degree. Otherwise it is also reminded that a current and continuous treatment with ICS increases the risk of Pneumonias at least in patients with severe COPD. Moreover, it is quoted the role of the triple association (LABA, LAMA and ICS) in improving the lung functions, in reducing the number of exacerbations and in improving the clinical general conditions.

Widening the analysis to other LAMAs it has to be quoted the action of umeclidinium both versus placebo, tiotropium and glycopirronium $[127,128]$. In all these cases umeclidinium showed a more important bronchodynamic effect, but all the molecules, less placebo, proved to be endowed of a good activity on the vital parameters. Umeclidinium demonstrated also a good reliability when coupled to vilanterol. This combination can easily reach different targets thanks to the complimentary actions of LAMA and LABA that support a complete bronchodilatory effect. Similar positive outcomes regarded the SaintGeorge Respiratory Questionnaire (SGRQ) along all the time of the study (169 days) [129]. The combination of umeclidinium $125 \mathrm{mcg} / \mathrm{vi}-$ lanterol $25 \mathrm{mcg}$ administered for 52 weeks proved a major preventive effect against the exacerbations in comparison with umeclidinium 125 alone in a random double-blind placebo controlled study [130]. Another interesting study [131] compared LABA/LAMA (indacaterol/glycopirronium) with a LABA/ICS (Salmetero//Fluticasone) with an important target like the prevention of exacerbations and the combination LABA/LAMA prevailed against the association LABA/ICS. The role of ICS in lowering the phlogosis has to be postulated considering the lower number of exacerbations when a combination of bechlomethasone $\mathrm{dip} /$ formoterol is compared with the action of the formoterol alone and similarly fluticasone furoate (FF) / vilanterol at the two dosages 100/25 and 200/25 demonstrated a solid bronchodynamic effect with a limited number of exacerbations [132]. The administration of 3 active substances such as Bechlomethasone/formoterol FF / glycopirronium through a single special device represent an impressive attempt to bring different substances endowed of complimentary actions to the proper targets in order to get a pharmachodynamic synergy. The study "Trilogy" [133] seems to give a frank support to this hypothesis. The triple combination obtained a significant success against the comparative association (BDP/FF) under important points of view: trough FEV1,
SGRQ, burden of exacerbations. It has also to be mentioned a possible novelty, at least under the molecular point of view, because this substance, GSK 961081, has a structure where at one extremity it is present an antimuscarinic part, while at the other extremity it exhibits a Beta2 stimulant action. So, the same molecule could exert a double and complimentary action [134]. Molecules like this could indicate a road to the future.

In summary combinations of LABAs/LAMAs, compared with placebo, causes improvement in FEV1 of 250-300 ml at peak and 250-300 at trough. These effects are greater than those obtained with long acting monotherapies alone. Moreover, important clinical questions are associated with these bronchodynamic effects: undoubtedly the treatment with LAMA/LABA positively influences dyspnea indexes, the complexity of St. George questionnaire, and reduces the number and severity of the exacerbations. As these substances are not primarily endowed of an antinflammatory power one might argue that the stability of airways reached by means of an effective treatment that leads to an improvement of lung mechanics can allow the patients to better cope with negative factors that trigger infections and exacerbations. This last point is also well contrasted with the correct use of ICS/LABA despite the increased risk of non-fatal pneumonias. If an association with LABA/ICS has a good effect in the prevention of exacerbations the association of ICS/LABA/LAMA can be, as recently proved, a very important resource in the inhalation therapy specially in the most difficult cases of COPD.

\section{A real-life observational study on homeopathic medicine preventive effect in respiratory tract infections}

The latest scientific literature found in leading biomedical databanks confirms that the trend towards what is referred to as "integrative healthcare" has grown constantly over the last 40 years [135].

There are many definitions of "integrative" healthcare, but all involve combining conventional and complementary approaches in a coordinated way. The use of integrative approaches to health and wellness has grown within care settings across the United States. Researchers are currently exploring the potential benefits of integrative healthcare in a variety of situations, including pain management for military personnel and veterans, relief of symptoms in cancer patients and survivors, and programs to promote healthy behavior [136].

As a rule, the use of homeopathic medicines in conventional therapies is seen in a positive light by patients. We used a recent American analysis, the 2012 National Health Interview Survey, to compare homeopathy users with supplement users and with those using other forms of complementary and integrative medicine. Among US adults, $2.1 \%$ had used homeopathy within the past 12 months. Respiratory and eye, ear nose and throat complaints were those most commonly treated (18.5\%). Homeopathy users were more likely to use multiple complementary and integrative therapies, and to perceive the therapy as helpful, than were supplement users. Though US homeopathy use remains relatively uncommon, users perceive it as helpful [135-137]. In terms of respiratory conditions, a number of different findings in Europe, and in particular in France and Germany, show that these treatments are well received by patients, providing them with an integrated approach to handling respiratory problems of viral origin, and especially influenza-like illnesses [138]. One example is a homeopathic medicine made from a Korsakovian dilution (200K) of a specific extract of duck liver and heart. Officially recognized in Italy by the AIFA [139] and also registered in other countries, such as France, where it has been authorized since 1944, it is sold in a total of over 80 countries throughout the world. 
In the Cochrane Collaboration review of homeopathic medicine, involving a meta-analysis [140] its preventive effect was found, based on the cumulative result of the meta-analysis, to be protective, but without reaching the statistically significant limit (overall risk ratio (RR) = $0.48 ; 95 \% \mathrm{CI}=0.17-1.34)$. Specifically, the first study reported a very low RR value of 0.15 (indicating an $85 \%$ reduction in the risk of getting sick), although the statistically significant limit was not reached; this can most likely be attributed to the low number of events ( $n=50$ patients in each group), which "enlarged" the confidence limits. The RR was also protective in the second study (which evaluated 110 patients treated with 0scillococcinum and 117 treated with placebo) and proved statistically significant, although it was less noticeable than the RR of the first study ( $R R=0.62$; thus, a risk reduction of $38 \%$ ). In my retrospective analysis [141] a significant reduction in the frequency of onset of RTIs was found in both the group treated with homeopathic medicine and the untreated groups. The reduction in the mean number of RTI episodes during the period of observation vs. the year before inclusion in the study was significantly greater in the homeopathictreated group than in untreated patients $(-4.76 \pm 1.45$ vs $-3.36 \pm 1.30$; $\mathrm{p}=0.001$ ). These results suggest that homeopathic medicine may have a positive effect in preventing RTIs. However, randomized studies are needed before any firm conclusion can be reached.

\section{The importance of inhaler device in patient management}

Asthma and COPD are two of the leading causes of morbidity, mortality and economic burden worldwide [20,103]. The World Health Organization (WHO) estimates that chronic respiratory diseases represent $5 \%$ of total disease burden and $8.3 \%$ of chronic disease burden worldwide, accounting for more than 4 million deaths each year [142]. Unsurprisingly, the economic cost associated with asthma and COPD is considerable, and has been shown to increase with disease severity $[20,103,142,143]$. Therefore, effective treatment and management of asthma and COPD is critical in improving clinical and economic outcomes.

Inhalation therapy is the mainstay of treatment in patients with asthma or COPD, where bronchodilators ( $\beta_{2}$ agonists, anti-muscarinic agents) and anti-inflammatory drugs (corticosteroids) are recommended by international strategy documents at any stage of the disease $[20,103]$. Inhaler devices, therefore, play a key role in the management of these patients and it is now recognized that the choice of the inhalation device appears to be as important as that of the drug molecule [144]. However, in daily clinical practice, while doctors usually focus on the pharmacological properties of the various respiratory drugs in selecting the best possible therapeutic option, little consideration is given to the features of the different inhalers and to the ability of the patient to use the device [145]. Indeed, it is often underappreciated that incorrect inhalation technique by the patient is directly associated with increased healthcare resource utilization [146].

Therapeutic aerosols can be generated essentially by three different delivery platforms: the pressurized metered dose inhaler (pMDI) where the drug is formulated in solution or suspension under pressure in a liquid propellant, and is released through an orifice upon device actuation; dry powder inhalers (DPIs), where the drug is formulated as a powder that is fluidized and entrained as aerosol particles by the patient's own inspiratory effort; nebulizers, for which the drug is formulated as a liquid and atomized into droplets using either a compressed air source attached to a narrow orifice to generate a Venturi effect or by more complex vibrating membranes [61,147]. Each type of inhaler device has pros, as well as, cons [148] and differs in its efficiency of drug delivery to the lungs, depending on the device characteristics, formulation of medication, and ease with which patients can use it $[61,147]$. Inhaler efficiency may also be influenced by patients' preference, which in turn affects patients' adherence with treatment and, indeed, long-term control of the disease [149-152]. Thus, the choice of the inhaler for the patient is just as important as choosing the most effective medication.

\section{Adherence in COPD}

It has been estimated that about half of all users of chronic medication take their medication according to their prescriber's recommendations [73]. A complicating factor for inhaled medication is that proper inhaler handling and technique is of paramount importance resulting in even lower real-world adherence rates compared to other chronic medications. Adherence rates for asthma and COPD are approximately $40 \%$ [73] but tend to be lower in adolescents and in patients with lower socioeconomic status [153]. Real-world evidence demonstrates that poor adherence to asthma and COPD treatment is associated with an increased number of exacerbations, and hospital admissions, as well as increased economic burden [154-156]. In addition, the rate of mortality linked to asthma decreased by $21 \%$ for each additional inhaler prescribed in the prior 12 months, demonstrating that better compliance can reduce mortality [157]. Similarly, adherence to inhaled medication is significantly associated with reduced risk of death and admission to hospital due to exacerbations in COPD [158].

\section{Inhaler misuse as a cause of poor adherence in asthma and COPD}

Many studies have shown a high proportion of inhaler misuse among patients with asthma or COPD, even in those patients who had been using their devices for long periods [159-162]. Moreover, no improvement over the past 40 years in the use of inhaler devices has been observed, even though considerable effort has been invested in education, training and device development [163]. These results support the major importance given to inhaler technique as a determinant of treatment effectiveness and, consequently, long-term adherence to respiratory inhaled medications.

Current inhaler devices require a complex administration procedure including dose loading, inhaler priming and breathing maneuver, in order to ensure maximal benefit of the medication. Multiple steps require that patients display dexterity and coordination [61,147]. Failure to follow the instructions may lead to inhalation errors, some of which reduce, or prevent entirely, deposition of the medication in the lungs [61,147]. In clinical studies, $50-90 \%$ of patients with asthma or COPD show incorrect inhaler technique [161-166]. In addition, even when patients are able to demonstrate correct inhaler technique, they may not maintain this standard at other times [161,162]. Complicating the situation further is the fact that the capacity for physicians and nurses to train the patient is often limited. Both time constraints and inadequate knowledge amongst health care professionals (HCPs) can lead to ineffective patient education. In a review of 20 relevant studies, only $28 \%$ of doctors and $22 \%$ of nurses were able to describe, or perform, all the critical steps for using inhalers [167].

Some patients appear to be at a greater risk of poor inhalation technique [166,168]. Some risk-factors relate to the patient: these include extreme ages (i.e., young children and the elderly), very severe airflow obstruction, cognitive dysfunction, motor handicap of the upper extremities; Other risk factors relate to the prescription and delivery of the treatment: patients who are simultaneously prescribed different types of devices (e.g., a pMDI and a DPI) tend to use their devices less 
appropriately than those using a single device type [169,170], and device switching without a face-to-face review is associated with worsening of asthma control $[170,171]$.

\section{Strategies to improve patients' inhaler use}

Ways to improve patients' adherence with inhalers are progressing inhaler design and use, training patients and individualizing inhaler choice.

\section{Developing the "ideal inhaler"}

The ideal inhaler should be user-friendly, deliver the optimal respirable amount of drug irrespective of the patient's skills, with limited need for external supervision and independently of environmental conditions. To date, none of the currently available inhalers can be considered "perfect" regarding these characteristics. Although some new inhalers simplify required dose preparation manipulation [148], patients still need some training and regular checking of inhalation technique. In addition, the multiplication of inhalation devices and corresponding instructions can be a source of confusion for HCPs who are not specialized in the respiratory area, such as many primary care physicians, even though they care for the majority of patients with asthma or COPD [172].

\section{Checking and training}

Several studies have shown that training patients in the correct inhaler use improves not only inhalation technique but also adherence to treatment and, most importantly, disease control [173-175]. Interestingly, studies found that disease outcomes improved only in those patients in whom inhaler technique improved following training by pharmacists, suggesting that the effect of training on control may actually be determined by the effect on inhaler technique [174,175]. However, it has also been shown that the effect of training is inconsistent and, sometimes, transient [176]. Several tools and strategies can be used to train both patients and HCPs in the correct use of inhaler devices [177]. Of note, some of them have been developed to help HCPs in checking inhalation technique and training patients since they provide real-time, interactive sensory feedback of the patient's performance in various critical aspects of inhalation technique, and estimate with reasonable accuracy the amount of aerosol delivered to the receptor sites [177]. It is important to recall that all HCPs (primary care physicians, lung specialists, nurses, physiotherapists, pharmacists) can be involved in training. In all cases, regular observation of the patient's own technique using his/her inhaler, demonstration of proper technique when necessary, followed by repeated observation of the patient ability to correct his/her technique should be considered an essential part of each patient consultation. More recently, evidence-based digital health solutions, such as monitoring systems based on phone applications (Apps) and electronic sensors have been developed to help patients with their care management via electronic dose counting, calendar reminders and in the measurement of physiological parameters [177].

\section{Personalizing device choice}

All patients with asthma or COPD do not require the same treatment, and all do not have the same skills and preferences. Therefore, tailoring the treatment to each specific patient is of utmost importance $[159,177,178]$. Several factors have to be taken into account when selecting a specific inhaler device for a specific patient.

These factors can be categorized as:

1. Patient-related factors, including i) age and ability to inhale consciously, handle the device and coordinate the use of the device and the inspiratory effort, ii) patient preference, iii) presence of comorbidities;
2. Disease-related factors, since i) severe and/or acute airflow obstruction may compromise the ability to generate an adequate inspiratory flow and ii) therapeutic strategy and indications are not the same for asthma and COPD;

3. Device-related factors, as the optimal inhalation profile differs between pMDIs (slow inspiration is preferable) and DPIs (fast flow inhalation is required). For instance, observational comparative effectiveness studies suggest that pMDIs delivering small droplet aerosols could improve treatment effectiveness compared to standard pMDIs [179], due to the more limited influence of errors in coordination/inhalation technique on lung deposition with these devices; and, finally;

4. Caregivers-related factors, accounting for the availability and knowledge of professionals involved in information and education.

\section{Conclusions}

Despite the range of effective pharmacological treatments available for asthma and COPD, many patients still do not achieve treatment goals, in part because of poor adherence to therapy. Non-adherence to treatment is associated with poor symptom control, higher healthcare utilization and healthcare costs, and reductions in health-related quality of life.

The inhaled route remains favored for the treatment of pulmonary diseases. However, drug deposition and subsequent treatment effectiveness are highly dependent on inhalation technique, which has been shown to be incorrect in many patients with asthma and COPD. Many inhalation devices are available and others are currently being developed with the aim of simplifying device use. Nonetheless, at present proper training and regular checking of inhalation technique remain critical to optimize treatment effectiveness. Optimizing treatment effectiveness also requires tailoring the drug-device combination chosen for each individual patient based on their individual characteristics, the disease treated and its severity, the characteristics of devices and the skills of involved healthcare professionals.

\section{Influence of comorbidities on adherence to treatment in COPD}

Patient adherence to treatment in chronic respiratory diseases as COPD is essential to optimize disease management. As with all chronic diseases, non-adherence in patients with chronic respiratory diseases is common and contributes to adverse health outcomes, reduced quality of life, increased morbidity, increased health care expenditures, unnecessary escalation in therapies and even hospitalizations and mortality [180-183].

In 2001, WHO defined adherence as the "extent to which a person's behavior taking medication, following a diet, and/or executing life style changes, corresponds with agreed recommendations from a health care provide" [73]. In this concept adherence is a complex concept, influenced by multiple factors including social and environmental, patient related and treatment related factors. Comorbidities are identified as one of the patient-related factors, besides health beliefs, cognitive ability, self-efficacy, psychological aspects and others [73].

More recently, the term concordance has been introduced to describe the therapeutic alliance between patients and health care providers [184]. Concordance encompasses the responsibility and decisionmaking contribution of both parties and empowers the patient to play an active role in disease management [1].

Multimorbidity is now widely recognized as a characteristic finding in many patients with Chronic respiratory diseases as COPD. Different studies have identified a wide spectrum of pathologies in these patient 
[184,185]. Polypharmacy is a common finding in these patients as medication is prescribed for all these identified medical conditions. This polypharmacy is a common and important contributor to poor adherence as each medication has a different dosing pattern. Patients get frustrated by these complicated dosing regimens [186]. Many of these drugs have no immediate or direct effect on symptoms and can have some side-effects. All these factors can contribute to poor adherence [187]. Conceptual frameworks are described to manage comorbidities beyond the lungs, but most of these reviews summarize current evidence but are not supported by real-life interventions [188]. Furthermore, adequate systematic diagnostic work-up according standard criteria is crucial to avoid under- or overtreatment of these multimorbidities [189].

Pulmonary rehabilitation aims to offer a comprehensive intervention based on thorough patient assessment followed by patient-tailored therapies, including behavior change, in order to achieve improvement in physical and psychological condition and to promote long-term adherence to health-enhancing behaviors [190]. Different studies, reviewed by Franssen and Rochester, have tried to assess the possible influence of comorbidities on outcome of pulmonary rehabilitation [191]. In a retrospective study, Crisafulli et al. identified that the improvement in exercise tolerance and quality of life may depend on identified comorbidities: metabolic diseases were inversely related to improvement in exercise tolerance with opposite effects of cardiac diseases. Otherwise, improvements in health status were inversely related to heart diseases [192]. In another prospective study, the same authors concluded that the individual's disability and presence of osteoporosis were independently associated with poorer rehabilitation outcomes [194]. Others reported that baseline status is a poor predictor of response to rehabilitation, although severely dyspneic patients showed smaller magnitudes of improvement [195].

Psychological factors are important determinants of outcome and adherence to pulmonary rehabilitation. Risk of drop-out during rehabilitation is significantly greater in depressed versus non-depressed patients and anxiety is associated with worse exercise performance, quality of life and shortness of breath in COPD patients [195-197]. A more recent study reported that common comorbidities, including anxiety and depression, do not influence the likelihood of improving following pulmonary rehabilitation. Moreover, patients identified as a psychological cluster with highest scores in anxiety and depression had a higher likelihood of achieving meaningful improvements after rehabilitation [198].

Adherence to all components of comprehensive treatments must be considered as an important goal for health care providers and patients to work towards optimal management and control of chronic respiratory conditions. Providers play an important role in helping patients to adhere with all the components of the management plan. Active involvement of the patients in defining management goals and partnership between the patient and the team of health care providers will improve adherence. Future research is needed to gain insights into determinants of adherence and sustainability of adherence during the continuum of care of these patients.

\section{Medication adherence in patients with COPD}

COPD is a chronic disease in which effective management requires long-term adherence to pharmacotherapies [199]. Regrettably, the level of medication adherence in COPD patients is very low, lower than that recorded for other diseases [200], although it must be pointed out that there are difficulties in understanding the real dimension of the problem and the causes that determine it because it problematic to compare the results of different studies carried out.
There are several approaches, such as biochemical evaluation of drug level to confirm the intake, electronic monitoring, adherence measured as the percentage of doses taken/doses prescribed, electronic monitoring, canister weight, and analysis of pharmacy records to assessing adherence of patients with COPD, but they are all burdened with important limitations [201]. It is also possible to indirectly measure adherence by using self-reported (questionnaires) adherence methods. It has been reported that although the prevalence of treatment adherence changes over time, the combination of the attitude towards treatment and the patient's knowledge of COPD is the best approach to test self-reported adherence [202]. However, it must be pointed out that self-reporting is frequently inaccurate and has moderate reliability (25\%-67\%) when compared against more objectives measures of adherence such as canister weight and electronic monitoring [203].

Patients, physicians and society influence patient maintenance medication adherence in COPD. Low expectation of the medication, presence of comorbid illnesses, depressed mood, increased age, current smoking, and lack of confidence in the provider are the most consistent independent predictors of low adherence [204]. Adherence to medications may be impacted by factors that do not change regardless of disease or medication type but reasonably is influenced by aspects of patient-related considerations (forgetfulness, suboptimal health knowledge, etc.), although also the health system (lack of coordinated health care, access restrictions, etc.) and socioeconomic status (education, income, etc.) can play a role [205]. In particular, the psychological profile is a key driver in determining adherence to medications in COPD patients [206]. Older age coupled with memory loss and impaired cognitive levels lowers adherence to medications, in particular to inhalation therapy [207].

The physician can affect adherence in COPD with his/her prescription because medication class to be administered, method of administration, dosing regimen, polypharmacy, and also the possible occurrence of adverse events can all influence compliance to prescribed therapy, although patient preference must always be considered a crucial factor when choosing drug, method of administration, and dosing regimen [208].

It is intriguing that a study performed in an area with a centralized management system of pharmacological prescriptions and aimed to assess the degree of adherence for once-daily and twice-daily regimens for administrating LAMAs, showed that adherence to treatment with LAMAs is very high, irrespective of the molecules or inhalation device, but did not find that patients who used twice-daily medication had a lower adherence [209]. The method of administration can affect the level of drug adherence in COPD. There is solid evidence that in COPD, adherence to inhalation medication is device-related [210]. Often physicians switch their patients to generic inhaled drugs to reduce costs. Switching from one device to another, if not accompanied by appropriate training for the patient, can be associated with poor clinical outcomes and increased use of health care resources [211]. Additionally, clinician's confidence about a patient's adherence to one class of medication should not be used as a proxy for adherence to other medications; rather, clinicians should inquire about adherence to each drug separately [212]. Frequently, health care systems create barriers to adherence by limiting access to health care, using a restricted formulary, switching to a different formulary, and having prohibitively high costs for drugs, co-payments, or both [213]. Socioeconomic status is an intriguing factor in the search for determinants of population-level non-adherence to COPD because of its associations with economic, social, and education-related factors [73]. Caregivers, especially spouses, may improve therapeutic adherence in COPD [214]. 
Patient-health care professional, especially patient-physician or patient-pharmacist communication is central to optimizing patient adherence [202]. Education of patients, along with better co-ordination of care, showed significant improvements on COPD patients' adherence [215] as well as fewer hospitalizations [216].

Interestingly, pragmatic pharmacist care programs improve both inhalation technique and medication adherence in patients with COPD and could reduce hospitalization rates [217]. This is a cost-saving strategy compared with usual care [218].

No standard intervention exists to improve adherence. However, it is likely that a multifactorial intervention focuses on motivation, knowledge and skilled inhalation technique (COPD information, dose reminders, audio-visual material, motivational aspects and training in inhalation techniques) is an effective approach to improving the therapeutic adherence in COPD patients [219]. In any case, adherence requires a behavioral change, an aspect that is related to individual interests and expectations, meaning that patients must be managed individually. Furthermore, the intervention is complex and time-consuming.

Although more research is needed into the most effective approaches for optimizing medication adherence in patients, mainly elders, with COPD, there are a number of practical opportunities for health care practitioners to intervene to support medication adherence [220]. However, it is likely that the most realistic approach is to keep in mind that non-adherence is always possible and probable [208].

\section{Adherence to COPD therapy: The Lombardy CREG (Chronic Related Group) experience}

CREG can be defined as an innovative way to care patients with chronic diseases. The innovative element which lead actors to focus on the life time horizon and think in terms of prevention is the CREG tariff. Against a payment of a default quota of resources, it must be ensured all services outside the hospital (outpatient, prosthetics, pharmaceutical, home care, etc.) required for good clinical and organizational management of chronic disease - or set of diseases [221] - and is aimed to ensuring the essential levels included in the various pathways of care. From the structural point of view, CREG is composed by three technological elements and an organizational platform: the first technological element is represented by the ability to identify the chronic illness; the second one is the PDT (Percorsi Diagnostici Terapeutici) that is to say the standard guidelines for any disease or set of diseases and the third one is a system of remuneration.

Particularly, there were define diseases of priority interest and some ASL (Bergamo, Como, Milan downtown, Melegnano, Lecco) in which to apply the specify path. COPD has considered one of the diseases of main interest [222]. The aim of the test has been to put the emphasis on the administrative, organizational, and management aspects, with the intent of identifying critical aspects, opportunities and operational solutions [224]. One of the most impressive data was the COPD therapy adherence. The "pact" between general practitioner and patient with the help of nurses, reached the goal to equalize the COPD adherence therapy rate to the diabetes and hypertension rate in two years [224].

The key aspect of the CREG, is represented by identification of subject that guarantees the continuity of the path, interacting with all the actors involved in the management of the disease and ensuring the necessary administrative, organizational and managerial skills (general practitioners, foundations, hospitals, etc.) which will be in charge for ensuring the full support of patients recruited to the path of CREG.
The most important expected outcome is in terms of the adequacy and appropriateness of care. That is through two channels: first patients (hypo consumers) who usually give up their pathway are leading to adherence to PDT; secondly, by avoiding the inappropriate medical consumption.

\section{State-of-the-art and open problems in COPD: Gaps and issues}

The main goals of COPD treatment are reducing current symptoms and future risks with minimal adverse effects by pharmacological treatments. The achievement of these objectives may be a challenge in daily clinical practice, where the level of adherence to treatment is low, with consequent poor control of the disease, and the occurrence of co-morbidities requires multiple drugs, with an increased risk of drug-drug interactions potentially leading to severe adverse effects. In addition, a significant discrepancy has been reported between guideline recommendations and clinicians' practices [224-226].

The currently available bronchodilator therapies approved for COPD are LABA (long-acting or ultra long-acting $\beta$-2 agonists) and LAMA (antimuscarinic agents). Bronchodilators are the mainstay of COPD treatment, as single agents, as dual combination, or associated with inhaled corticosteroids (ICS). Until last year, the latter represented the firstchoice treatment for stable COPD in the most severe stages of the disease (GOLD stage $C$ and D). The newest GOLD recommendations [103] set the ICS/LABA as alternative choice when exacerbations persist despite treatment with LABA/LAMA. Nevertheless, the management of COPD patients by general practitioners (GPs) and by specialists in real life settings is often characterized by inappropriateness of prescribing the ICS/LABA combination in patients with mild or moderate COPD [227]. The use of ICS must be carefully evaluated, since it has been associated with an increased risk of developing pneumonia, which is greatest in the very elderly and at the highest doses [227].

A variable proportion of the COPD population does not control the disease because of factors that include inadequate drug treatment, and lack of adherence to the recommended drug therapy or to the device. In addition, physicians and patients tend to underestimate the intensity and frequency of respiratory symptoms, and the need to monitor the disease. Overall, the occurrence of inadequate physician-patient communication is the main factor that contributes to the lack of optimal control. The lack of adherence to therapy strongly impacts on the control of the disease. Indeed, the aim of inhaled therapy is to allow the medication to reach the target site. This can be attained by ensuring the penetration of the aerosolized particles into the lower respiratory tract, and the deposition of the drug along the bronchial tree. Obviously, the deposition of the drug should translate into functional and clinical benefits. Taken together, these conditions lead to the fact that the right choice of the (right) device becomes crucial. The devices differ in terms of technical design (required inspiratory flow rate, actuation), composition (characteristics of the propellant, carrier substances), dose per inhalation, and costs. In addition, major efforts have been devoted by the producer on the user-friendliness of the device [61]. The relative deposition pattern of the inhaled drug is the result of a complex interaction between the aerosol formulation and the device used. In the suspension formulation, the active drug is not-soluble in the propellant and remains as solid powder; therefore, suspension formulations need to be shaken before inhalation to allow uniform distribution of solid powder particles of the drug. It has been demonstrated that a significant proportion of patients do not shake properly the device or present with coordination problems [228], resulting in variable amount of emitted drug in each aerosol puff. The occurrence of mistakes associ- 
ated with the inhalation procedures can be reasonably reduced by regular training and follow-up. Patients are not completely satisfied with physician behaviors, and often do not trust the pharmacological treatment. Therefore, the choice of the inhaler is the result of an alliance between the physician and the patient, who agree on the needs and expectations. Not all device can fit the patients' skills; as discussed below, the concomitant extra-pulmonary conditions and older ages can variably affect the ability to properly use the inhaler [229].

Another reason for the inadequate control of COPD has to be identified in the unsatisfactory collaboration between specialists and GPs. In this regard, a recent explorative investigation showed that implementing the collaboration between GPs and pulmonologists may enhance the diagnostic process towards COPD [230]. The so-called "COPD action" experience based on a pro-active approach to the individuals attending the primary care offices followed by an in-house intervention by specialists could serve as a model for larger interventional approaches to unveil undiagnosed chronic obstructive lung diseases. One of the gaps that needs to be filled is the implementation of the use of lung function assessment in individuals with suspected COPD and/or in the follow-up of subjects with an ascertain diagnosis of COPD. In this respect, although international guidelines recognize the use of spirometry as the gold standard for confirming the presence of irreversible airflow limitation and diagnosing COPD in reproducible, standardized, and objective way, only a proportion of GPs has been shown to use spirometric criteria to define COPD [231].

COPD is characterized by the presence of comorbid conditions. Comorbidities have a potent influence on the therapeutic management of COPD. Due to the prevalence of early onset of comorbidities in COPD, an early treatment of the disease could be suggested to prevent the burden of comorbid conditions, even if further studies are still required to confirm the efficacy of this approach. For example, an increased risk of cardiovascular disorders has been recently documented in smoker subjects who are symptomatic but have not developed airway obstruction [232]. It has been suggested that the long-lasting exposure to smoke is the driving factor that initiates the inflammatory process both in the lungs and in the arteries, which in turn promotes the excess cardiovascular risk in chronic respiratory patients.

Clinical practice guidelines, the backbones of evidence-based medicine, are based upon the results of meta-analyses and randomized clinical trials (RCTs). In order to exclude potential confounding factors that may affect the results of the RCTs, restrictive inclusion/exclusion criteria are usually applied for recruitment of the sample. However, highly selected "pure" study populations might not be fully representative of larger, unselected, patients attending the outpatient clinics in the real-life setting. As a consequence, the extrapolation of the RCTs results to the everyday clinical practice could be potentially limited. In asthma, more than $40 \%$ of subjects with mild/moderate disease are currently treated by protocols based on the results of RCTs for which they would have not been eligible [233]. This proportion increases in elderly patient with comorbidities. In COPD, more than $80 \%$ of subjects with COPD are currently treated by protocols based on results of RCTs for which they would have not been eligible [234]. These findings limit the generalizability of RCTs and advocate for complementary pragmatic studies.

\section{References}

1. Proceedings of the European Seminars in Respiratory Medicine (June 27-July 2, 1998). Monaldi Arch Chest Dis 1998;53:603-719.

2. Proceedings of the European Seminars in Respiratory Medicine (July 2-6, 1999). Monaldi Arch Chest Dis 1999;54:463-558.
3. Donner CF, Carrozzi L, Maio S, et al. Integrating the care of the complex COPD patient. Proceedings of the European Seminars in Respiratory Medicine course, Long-Term Integrated Care of COPD Patients (June 2016). Monaldi Arch Chest Dis 2017;83:786.Mona

4. Simoni M, Baldacci S, Maio S, et al. Mortalità per malattie respiratorie in Italia (1990-2010). Parte I: Metodi e tassi grezzi nazionali e per regione. Rassegna Patologia Apparato Respiratorio 2014;29:200-206.

5. WHO. European Detailed Mortality Database. Available from: http://data.euro.who.int/dmdb

6. WHO. European Hospital Morbidity Database. Available from: http://data.euro.who.int/hmd

7. Ministero della Salute. Ricoveri Ospedalieri (SD0). Available from: http://www.salute.gov.it/portale/temi/p2_4.jsp?area=ricoveri Ospedalieri

8. Viegi G, Pistelli F, Sherrill DL, et al. Definition, epidemiology and natural history of COPD. Eur Respir J 2007;30:993-1013.

9. Adeloye D, Chua S, Lee C, et al. Global Health Epidemiology Reference Group (GHERG). J Glob Health 2015;5:020415.

10. Maio S, Sherrill DL, MacNee W, et al. The ERS Spirometry Tent: a unique form of screening for airway obstruction. Eur Respir J 2012;39:1458-67.

11. Viegi G, Maio S, Pistelli F, et al. Epidemiology of chronic obstructive pulmonary disease: health effects of air pollution. Respirology 2006;11:523-532.

12. Viegi G, Mattelli G, Angino A, et al. The proportional Venn diagram of obstructive lung disease in the Italian general population. Chest 2004;126:1093-101.

13. Maio S, Baldacci S, Carrozzi L, et al. Respiratory symptoms/diseases prevalence is still increasing: a $25 \mathrm{yr}$ population study. Respir Med 2016;110:58-65.

14. Simoni M, Pedreschi M, Baldacci S, et al. The Po river Delta epidemiological study: use of medicines in a general population sample of North Italy. Pharmacoepidemiol Drug Saf 2000; 9:313-26.

15. Simoni M, Carrozzi L, Baldacci S, et al. Respiratory symptoms/diseases, impaired lung function, and drug use in two Italian general population samples. Respir Med 2008;102:82-91.

16. Maio S, Baldacci S, Martini F, et al. COPD management according to old and new GOLD guidelines: an observational study with Italian general practitioners. Curr Med Res Opin 2014;30:1033-42.

17. Maio S, Simoni M, Baldacci S, et al. The ARGA study with Italian general practitioners: prescriptions for allergic rhinitis and adherence to ARIA guidelines. Curr Med Res Opin 2012;28:1743-51.

18. Akdis CA, Ballas ZK. Precision medicine and precision health: Building blocks to foster a revolutionary health care model. J Allergy Clin Immunol 2016;137:1359-61.

19. Fahy JV. Type 2 inflammation in asthma - present in most, absent in many. Nat Rev Immunol 2015;15:57-65.

20. GINA (Global Initiative for Asthma). Global strategy for asthma management and prevention. Available from: www.ginasthma.org

21. de Groot JC, Ten Brinke A, Bel EH. Management of the patient with eosinophilic asthma: a new era begins. ERJ Open Res 2015;1.pii: 00024-2015.

22. Dente FL, Latorre M, Novelli F, et al. Can sputum Eosinophilia be a constant feature in severe refractory asthmatics? A 3-year longitudinal study. Int Arch Allergy Immunol 2015;166:287-90.

23. Bacci E, Latorre $M$, Cianchetti $S$, et al. Transient sputum eosinophilia may occur over time in non-eosinophilic asthma and this is not prevented by salmeterol. Respirology 2012;17:1199-206.

24. Demoly P, Annunziata K, Gubba E, Adamek L. Repeated cross-sectional survey of patient-reported asthma control in Europe in the past 5 years. Eur Respir Rev 2012;21:66-74. 
25. Demoly P, Paggiaro P, Plaza V, et al. Prevalence of asthma control among adults in France, Germany, Italy, Spain and the UK. Eur Respir Rev 2009;18:105-1.

26. Papi A, Canonica GW, Maestrelli P, BEST Study Group. Rescue use of beclomethasone and albuterol in a single inhaler for mild asthma. N Engl J Med 2007;356:2040-52.

27. Papi A, Nicolini G, Baraldi E, BEST for Children Study Group. Regular vs prn nebulized treatment in wheeze preschool children. Allergy 2009;64:1463-71.

28. Papi A, Marku B, Scichilone N, AIFASMA Study Group. Regular versus as-needed budesonide and formoterol combination treatment for moderate asthma: a non-inferiority, randomised, doubleblind clinical trial. Lancet Respir Med 2015;3:109-19.

29. 0'Byrne PM, Fitzgerald JM, Zhong N, et al. The SYGMA programme of phase 3 trials to evaluate the efficacy and safety of budesonide/formoterol given 'as needed' in mild asthma: study protocols for two randomised controlled trials. Trials 2017;10;18:12.

30. 0'Byrne PM, Pedersen S, Lamm CJ, START Investigators Group. Severe exacerbations and decline in lung function in asthma. Am J Respir Crit Care Med 2009;179:19-24.

31. Humbert M, Andersson TL, Buhl R. Budesonide/formoterol for maintenance and reliever therapy in the management of moderate to severe asthma. Allergy 2008;63:1567-80.

32. Papi A, Corradi M, Pigeon-Francisco C, et al. Beclometasone-formoterol as maintenance and reliever treatment in patients with asthma: a double-blind, randomised controlled trial. Lancet Respir Med 2013;1:23-31.

33. Tattersfield AE, Postma DS, Barnes PJ, et al. Exacerbations of asthma: a descriptive study of 425 severe exacerbations. The FACET International Study Group. Am J Respir Crit Care Med 1999;160:594-9.

34. Virchow JC, Backer V, Kuna P, et al. Efficacy of a house dust mite sublingual allergen immunotherapy tablet in adults with allergic asthma: A randomized clinical trial. JAMA 2016;315:1715-25.

35. Humbert M, Busse W, Hanania NA, et al. Omalizumab in asthma: an update on recent developments. J Allergy Clin Immunol Pract 2014;2:525-36.

36. Bacci E, Cianchetti S, Bartoli M, et al. Low sputum eosinophils predict the lack of response to beclomethasone in symptomatic asthmatic patients. Chest 2006;129:565-72.

37. Louis R, Demarche S, Schleich F. A historical perspective: Are inhaled corticoids sufficient to control asthma? J Transl Int Med 2015;3:113-5.

38. Iwamoto H, Yokoyama A, Shiota N, et al. Tiotropium bromide is effective for severe asthma with noneosinophilic phenotype. Eur Respir J 2008;31:1379-80.

39. Shrimanker R, Pavord ID. Interleukin-5 Inhibitors for severe asthma: rationale and future outlook. BioDrugs 2017;31:93-103.

40. Kau AL, Korenblat PE. AntilL5 Anti-interleukin 4 and 13 for asthma treatment in the era of endotypes. Curr Opin Allergy Clin Immunol 2014;14:570-5.

41. Ruggeri I, Bregato D, Colombo GL, et al. Cost and appropriateness of treating asthma with fixed-combination drugs in local health care units in Italy. ClinicoEcon Outcomes Res 2012;4:375-82.

42. Nunes C, Pereira AM, Morais-Almeida M. Asthma costs and social impact. BMC Asthma Res Pract 2017;3:1.

43. Accordini S, Corsico A, Cerveri I, et al. The socioeconomic burden of asthma is substantial in Europe. Allergy 2008;63:116-24.

44. Dal Negro RW, Micheletto C, Tosatto R, et al. Costs of asthma in Italy: results of the SIRIO (Social Impact of Respiratory Integrated Outcomes) study. Respir Med 2007;101:2511-9.
45. Borghi C, Cicero AFG. Aderenza e persistenza in terapia [Adherence and persistence in therapy]. Giornale Italiano di farmacoeconomia e farmaco utilizzazione 2008;1:5-13.

46. Catapano AL, Casula M, Tragni E. Indicatori di appropriatezza prescrittiva per la valutazione della qualità assistenziale [Indicators of appropriateness for the assessment of quality of care]. CARE 2010;6:33-5.

47. Casula M, Tragni E, Catapano AL. I database amministrativi come fonti di dati per la ricerca farmaco epidemiologica. CARE I. [The administrative databases as data sources for epidemiological research drug. CARE I]. 2011:33-36.

48. Cheong C, Barner JC, Lawson KA, Johnsrud MT. Patient adherence and reimbursement amount for antidiabetic fixed-dose combination products compared with dual therapy among Texas Medicaid recipients. Clin Ther 2008;30:1893-907.

49. Holgate S, Bisgaard H, Bjermer L, et al. The Brussels Declaration: the need for chance in asthma management. Eur Respir J 2008; $32: 1433-42$.

50. Cochrane MG, Bala MV, Downs KE, et al. Inhaled corticosteroids for asthma therapy: patient compliance, devices, and inhalation technique. Chest 2000;117:542-50.

51. Ernst P. Inhaled drug delivery: a practical guide to prescribing inhaler devices Can Respir J 1998;5:180-3.

52. Broeders ME, Molema J, Vermue NA, Folgering HT. Peak inspiratory flow rate and slope of the inhalation profiles in dry powder inhalers. Eur Respir J 2001;18:780.

53. Pedersen S, Hansen OR, Fuglsang G. Influence of inspiratory flow rate upon the effect of a Turbohaler. Arch Dis Child 1990;65:308-10.

54. Kerstjens HA, Disse B, Schröder-Babo W, et al. Tiotropium improves lung function in patients with severe uncontrolled asthma: a randomized controlled trial. J Allergy Clin Immunol 2011;128:308.

55. Panos RJ. Efficacy and safety of eco-friendly inhalers: focus on combination ipratropium bromide and albuterol in chronic obstructive pulmonary disease. Int $\mathrm{J}$ Chron Obstruct Pulmon Dis 2013;8:221-30.

56. Nimmo CJ, Che DN, Martinusen SM. Assessment of patient acceptance and inhalation technique of a pressurized aerosol inhaler and two breath-actuated devices. Ann Pharmacother 1993;27:922-7.

57. Onyirimba F, Apter A, Reisine S. Direct clinician-to-patient feedback discussion of inhaled steroid use: its effect on adherence. Ann Allergy Asthma Immunol 2003;90:411-5.

58. Tachemura M, Kobayashi M, Kimura K, et al. Repeated instruction on inhalation technique improves adherence to therapeutic regimen in asthma. J Asthma 2010;47:202-8.

59. Armour C, Bosnic-Anticevich S, Brilliant M, et al. Pharmacy asthma care program improves outcomes for patients in the community. Thorax 2007;62:496-502.

60. Ram FS, Wright J, Brocklebank D, White JE. Systematic review of clinical effectiveness of pressurised metered dose inhalers versus other hand held inhaler devices for delivering beta (2) agonists bronchodilators in asthma. BMJ 2001;323:901.

61. Dolovich MB, Ahrens RC, Hess DR, et al. Device selection and outcomes of aerosol therapy: Evidence-based guidelines: American College of Chest Physicians/American College of Asthma, Allergy, and Immunology. Chest 2005;127:335.

62. Papi A, Haughney J, Virchow JC, et al. Price inhaler devices for asthma: a call for action in a neglected field. Eur Respir $\mathrm{J}$ 2011;37:982-5.

63. Pinnock H, Thomas M, Tsiligianni I, et al. The International Primary Care Respiratory Group (IPCRG) Research Needs Statement 2010. Prim Care Resp J 2010;19(Suppl 1):S1-20. 
64. The European White Lung Book. Respiratory health and disease in Europe. Adult asthma. European Respiratory Society 2013; p. 138-147.

65. WHO. Asthma. Accessed: June 2017. Available from: http://www. who.int/mediacentre/factsheets/fs307/en/

66. GINA (Global Initiative for Asthma). Global Strategy for Asthma Management and Prevention, 2017 Report. Accessed: June 2017. Available from: http://ginasthma.org/2017-gina-report-globalstrategy-for-asthma-management-and-prevention/

67. National Institute for Health and Care Excellence. Accessed: June 2017. July Available from: https://www.nice.org.uk/guidance/indevelopment/gid-cgwave0743

68. Bateman ED, Boushey HA, Bousquet J, et al. Can guideline-defined asthma control be achieved? The Gaining Optimal Asthma ControL Study. Am J Respir Crit Care Med 2004;170:836-844.

69. D'Urzo A. The GOAL study. Can Fam Physician 2006;52:187-9.

70. Cerveri I, Locatelli F, Zoia MC, et al. International variations in asthma treatment compliance: the results of the European Community Respiratory Health Survey (ECRHS). Eur Respir J 1999;14:288-24.

71. Horne R. Compliance, adherence, and concordance: implications for asthma treatment. Chest 2006;130(Suppl.1):S65-72.

72. Sabate E. WHO Adherence Meeting Report. Geneva, World Health Organization, 2001.

73. WHO. Adherence to long-term therapies. Evidence for action. World Health Organization, 2003.

74. National Community Pharmacists Association. Medication adherence in America: A national report card. Accessed: June 2017. July Available from: http://www.ncpanet.org/pdf/reportcard/Adherence ReportCard_Full.pdf

75. Chisholm-Burns MA, Spivey CA. The 'cost' of medication nonadherence: consequences we cannot afford to accept. J Am Pharm Assoc 2012;52:823-6.

76. Gamble J, Stevenson M, McClean E, et al. The prevalence of nonadherence in difficult asthma. Am J Respir Crit Care Med 2009;180:817-22.

77. Reid D, Abramson M, Raven J, Walters HE. Management and treatment perceptions among young adults with asthma in Melbourne: the Australian experience from the European Community Respiratory Health Survey. Respirology 2000;5:281-7.

78. Breekveldt-Postma NS, Koerselman J, Erkens JA, et al. Treatment with inhaled corticosteroids in asthma is too often discontinued. Pharmacoepidemiol Drug Sa 2008;17:411-22.

79. Inhaler Error Steering Committee, Price D, et al. Inhaler competence in asthma: common errors, barriers to use and recommended solutions. Respir Med 2013;107:37-46.

80. Engelkes M, Janssens HM, de Jongste JC, et al. Medication adherence and the risk of severe asthma exacerbations: a systematic review. Eur Respir J 2015;45:396-407.

81. Moullec G, Gour-Provencal G, Bacon SL, et al. Efficacy of interventions to improve adherence to inhaled corticosteroids in adult asthmatics: Impact of using components of the chronic care model. Respir Med 2012;106:1211-25.

82. U.S. Department of Health and Human Services, Office of Disease Prevention and Health Promotion. Healthy people 2010. Washington, DC: US Government Printing Office; 2000.

83. Rosas-Salazar C, Apter AJ, Canino G, Celedón JC. Health literacy and asthma. J Allergy Clin Immunol 2012; 29:935-42.

84. Gibson PG, Powell H, Coughlan J, et al. Limited (information only) patient education programs for adults with asthma. Cochrane Database Syst Rev 2002;CD001005.

85. Lavoie KL, Moullec G, Lemiere C, et al. Efficacy of brief motivational interviewing to improve adherence to inhaled corticos- teroids among adult asthmatics: results from a randomized controlled pilot feasibility trial. Patient Preference Adherence 2014;8:1555-69.

86. An SS, Bai TR, Bates JH, Black JL, et al. Airway smooth muscle dynamics: a common pathway of airway obstruction in asthma. Eur Respir J 2007;29:834-60.

87. Pellegrino R, Viegi G, Brusasco V, et al. Interpretative strategies for lung function tests. Eur Respir J 2005;26:948-68.

88. Falaschetti E, Laiho J, Primatesta P, et al. Prediction equations for normal and low lung function from the Health Survey for England. Eur Respir J 2004;23:456-63.

89. Tashkin DP, Celli B, Decramer M, et al. Bronchodilator responsiveness in patients with COPD. Eur Respir J 2008;31:742-50.

90. Pellegrino R, Antonelli A, Crimi E, et al. Dependence of bronchoconstrictor and bronchodilator responses on thoracic gas compression volume. Respirology 2014;19:1040-5.

91. Postma DS, Kerstjens HA. Characteristics of airway hyperresponsiveness in asthma and chronic obstructive pulmonary disease. Am J Respir Crit Care Med1998;158:S187-92.

92. Cosio BG, Soriano JB, López-Campos JL, et al. Defining the asthma-COPD overlap syndrome in a COPD Cohort. Chest 2016;149:45-52.

93. Baarnes CB, Andersen ZJ, Tjønneland A, et al Incidence and longterm outcome of severe asthma-COPD overlap compared to asthma and COPD alone: a 35-year prospective study of 57,053 middle-aged adults. Int J COPD 2017;12:571-9.

94. Que CL, Kenyon CM, Olivenstein R, Macklem PT, et al. Homeokinesis and short-term variability of human airway caliber. J Appl Physiol (1985) 2001;91:1131-41.

95. Chung KF, Wenzel SE, Brozek JL, et al. International ERS/ATS guidelines on definition, evaluation and treatment of severe asthma. Eur Respir J 2014;43:343-73.

96. Price D, Fletcher M, van der Molen T. Asthma control and management in 8000 European patients: the REcognise Asthma and LInk to Symptoms and Experience (REALISE) survey. NPJ Prim Care Respir Med 2014;24:14009.

97. Westerik JAM, Carter V, Chrystyn H, et al. Characteristics of patients making serious inhaler errors with a dry powder inhaler and association with asthma-related events in a primary care setting. J Asthma 2016;53:321-9.

98. Levy ML, Dekhuijzen PNR, Barnes PJ et al. Inhaler technique: facts and fantasies. A view from the Aerosol Drug Management Improvement Team (ADMIT). Npj Primary Care Respir Med 2016;26:16017.

99. Melani AS, Bonavia M, Cilenti V, et al. Inhaler mishandling remains common in real life and is associated with reduced disease control. Respir Med 2011;105:930-88.

100. Price DB, Román-Rodríguez M, McQueen RB, et al. Inhaler errors in the CRITIKAL Study: Type, frequency, and association with asthma outcomes. J Allergy Clin Immunol Pract 2017;pii: S22132198.

101. Lavorini F, Pedersen S, Usmani OS, et al. Dilemmas, confusion, and misconceptions related to small airways directed therapy. Chest 2016;pii: S0012-3692(16)53753-2.

102. Global Initiative for Chronic Obstructive Lung Disease (GOLD). Gold Reports 2017. Available from: http:/goldcopd.org/

103. Masoli M, Fabian D, Holt S, et al. The global burden of asthma: executive summary of the GINA Dissemination Committee report. Allergy 2004;59:469-78.

104. Lopez AD, Shibuya K, Rao C, et al. Chronic obstructive pulmonary disease: current burden and future projections. Eur Respir J 2006;27: 397-412. 
105. Partridge MR, van der Molen T, Myrseth SE, et al. Attitudes and actions of asthma patients on regular maintenance therapy: the INSPIRE study. BMC Pulm Med 2006:6:13.

106. Demoly P, Annunziata K, Gubba E, Adamek L. Repeated cross-sectional survey of patient-reported asthma control in Europe in the past 5 years. Eur Respir Rev 2012;21:66-74.

107. Haughney J, Price D, Kaplan A, et al. Achieving asthma control in practice: understanding the reasons for poor control. Respir Med 2008;102:1681-93.

108. Herland K, Akselsen JP, Skjønsberg OH, Bjermerd L. How representative are clinical study patients with asthma or COPD for a larger "real life" population of patients with obstructive lung disease? Respir Med 2005;99:11-9.

109. Sherman RE, Anderson SA, Dal Pan GJ, et al. Real-world evidence - What Is it and what can it tell us? N Engl J Med 2016;375:2293-7.

110. Giraud V, Roche N. Misuse of corticosteroid metered-dose inhaler is associated with decreased asthma stability. Eur Respir J 2002;19:246-51.

111. Molimard M, Raherison C, Lignot S, et al. Chronic obstructive pulmonary disease exacerbation and inhaler device handling: reallife assessment of 2935 patients. Eur Respir J 2017;49(2): pii: 1601794. doi: 10.1183/13993003.01794-2016.

112. Westerik JA, Carter V, Chrystyn H, et al. Characteristics of patients making serious inhaler errors with a dry powder inhaler and association with asthma-related events in a primary care setting. J Asthma 2016;5:321-9.

113. Bosnic-Anticevich S, Chrystyn H, Costello RW, et al. The use of multiple respiratory inhalers requiring different inhalation techniques has an adverse effect on COPD outcomes. Int J Chron Obstruct Pulmon Dis 2017;12:59-71.

114. Corradi M, Chrystyn H, Cosio BG, et al. NEXThaler, an innovative dry powder inhaler delivering an extrafine fixed combination of beclometasone and formoterol to treat large and small airways in asthma. Expert Opin Drug Deliv 2014;1:1497-506.

115. Grant AC, Walker R, Hamilton M, et al. The ELLIPTA ${ }^{\circledR}$ Dry powder inhaler: Design, functionality, in vitro dosing performance and critical task compliance by patients and caregivers. J Aerosol Med Pulm Drug Deliv 2015;28:474-85.

116. Voshaar T, Spinola M, Linnane P, et al. Comparing usability of NEXThaler ${ }^{\circledR}$ with other inhaled corticosteroid/long-acting beta2agonist fixed $\mathrm{c}$ inetics and pharmacodynamics of inhaled corticosteroids to asthma. Eur Respir J 2006;28:1042-50.

117. Bosnic-Anticevich S, Callan C, Chrystyn H, et al. Inhaler technique mastery and maintenance in healthcare professionals trained on different devices. J Asthma 2018;55:79-88.

118. Price D, Haughney J, Sims E, et al. Effectiveness of inhaler types for real-world asthma management: retrospective observational study using the GPRD. J Asthma Allergy 2011;4:37-47.

119. Derendorf H, Nave R, Drollmann A, et al. Relevance of pharmacokinetics and pharmacodynamics of inhaled corticosteroids to asthma. Eur Respir J 2006;28:1042-50.

120. Sonnappa S, McQueen B, Postma DS, et al. Extrafine versus fine inhaled corticosteroids in relation to asthma control: A systematic review and meta-analysis of observational real-life studies. J Allergy Clin Immunol Pract 2017; pii: S2213-2198(17)30557-3.

121. Dirkje S, Postma AK, Soriano JB, et al. Cohort analysis of exacerbation rates in adolescent and adult patients initiating inhaled corticosteroids for asthma: Different dose-response profile by particle size. Pulm Ther 2017;3;113-24.

122. Hodder R, Price D. Patient preferences for inhaler devices in chronic obstructive pulmonary disease: experience with Respimat Soft Mist inhaler. Int J Chron Obstruct Pulmon Dis 2009;4:381-90.
123. Bender BG, Long A, Parasuraman B, et al. Factors influencing patient decisions about the use of asthma controller medication. Ann Allergy Asthma Immunol 2007;98:322-8.

124. D'Arcy S, MacHale E, Seheult J, et al. A method to assess adherence in inhaler use through analysis of acoustic recordings of inhaler events. PLoS One 2014;9:e98701.

125. Foster JM, Usherwood T, Smith L, et al. Inhaler reminders improve adherence with controller treatment in primary care patients with asthma. J Allergy Clin Immunol 2014;134:1260-8.

126. Vogelmeir JF, Criner GJ, Martinez F, et al. Global strategy for diagnosis, management and prevention of Chronic Obstructive Lung Disease. 2017 Report Gold executive summary. Am J Resp Crit Care Med 2017;195:557-82.

127. Trivedi R, Richard N, Mehta R, Church A. Umeclidinium in patients with COPD a randomised, placebo controlled study. Eur Resp J 2014;43:72-81.

128. Rheault T, Khindri S, Vahdati-Boulori M, et al. A randomized open label study of umeclidinium versus glycopirronium in patients with COPD. ERJ Open Res 2016:2:00101-2015.

129. Maleki-Yadzi MR, Kaelin T, Richard N, et al. Efficacy and safety of umeclidinium/vilanterol $62.5 / 25 \mathrm{mcg}$. and tiotropium $18 \mathrm{mcg}$. in chronic obstructive pulmonary disese: result of a 24 week, randomized controlled trial. Resp Med 2014;108:1752-60.

130. Donohue JF, Niewoehner D, Brooks J, et al. Safety and tolerability of once daily umeclidinium/vilanterol 125/25 and umeclidinium $125 \mathrm{mcg}$ in patients with chronic obstructive pulmonary disease: results from 52 week randomized double blind placebo controlled study. Resp Res 2014;15:78

131. Wedzicha JA, Banerji D, Chapman KR, et al. Indacaterol/ glycopirronium versus salmeterol/fluticasone for COPD. NEJM 2016;374:2222-34.

132. Martinez F, Boscia J, Feldman G, et al. Fluticasone furoate/ vilanterol 100/25 200/25 improves lung function in COPD a randomized trial. Resp Med 2013;107:550-9.

133. Singh D, Papi A, Corradi M, et al. Single inhaler triple therapy versus inhaled corticosteroid plus long acting Beta2 agonist therapy for chronic obstructive pulmonary disease (Trilogy): a double blind parallele group, randomised controlled trial. Lancet 2016;388:963-73.

134. Wielders P, Ludwig-Sengpiel A, Locantore N, et al. A new class of bronchodilator improves lung function in COPD: a trial with GSK 961081. Eur Resp J 2013;42:972-81.

135. Treister-Goltzman Y, Peleg R. Trends in publications on complementary and alternative medicine in the medical literature. $\mathrm{J}$ Complement Integr Med 2015;12:111-5.

136. U.S. Department of Health and Human Services. NCCIH 2016 Strategic Plan. Available from: https://nccih.nih.gov/about/strategic-plans/2016

137. Dossett ML, Davis RB, Kaptchuk TJ, Yeh GY. Homeopathy use by US adults: Results of a national survey. Am J Public Health 2016;106:743-5.

138. Grimaldi-Bensouda L, Bégaud B, Rossignol M, et al. Management of upper respiratory tract infections by different medical practices, including homeopathy, and consumption of antibiotics in primary care: the EPI3 cohort study in France 2007-2008. PloS One 2014:19; 889990 .

139. Marrari LA, Terzan L, Chaufferin G. Oscillococcinum for influenza treatment. Ann. Ist. Super Sanità 2012;48:105-9.

140. Mathie RT, Frye J, Fisher P Homeopathic Oscillococcinum ${ }^{\circledR}$ for preventing and treating influenza and influenza-like illness. Cochrane Database Syst Rev 2015;28;1:CD001957

141. Beghi GM, Morselli-Labate AM. Does homeopathic medicine have a preventive effect on respiratory tract infections? A real life observational study. Multidiscip Respir Med 2016;21:11-2. 
142. WHO. Global surveillance, prevention and control of chronic respiratory diseases: A comprehensive approach. World Health Organization, Geneva, Switzerland; 2007.

143. Haahtela T. The disease management approach to controlling asthma. Respir Med 2002;96(Suppl A):S1e8.

144. Lavorini F, Usmani OS. Correct inhalation technique is critical in achieving good asthma control. Prim Care Respir J 2013;22:385-6.

145. Smaldone G, Berkland C, Gonda I, et al. Ask the experts: The benefits and challenges of pulmonary drug delivery. Ther Deliv 2013;4:905-13.

146. Melani AS, Bonavia M, Cilenti V, et al. Inhaler mishandling remains common in real life and is associated with reduced disease control. Respir Med 2011;105:930-8.

147. Laube BL, Janssens HM, de Jongh FHC, et al. What the pulmonary specialist should know about the new inhalation therapies. Eur Respir J 2011;37:1308-31.

148. Lavorini F, Fontana GA, Usmani OS. New inhaler devices - the good, the bad and the ugly. Respiration 2014;88:3-15.

149. Lavorini F, Fontana GA. Inhaler technique and patient's preference for dry powder inhaler devices. Exp Opin Drug delivery 2014;11:1-3.

150. Chrystyn H, Small M, Milligan G, et al. Impact of patients' satisfaction with their inhalers on treatment compliance and health status in COPD. Respir Med 2014;108:358-65.

151. Kozma CM, Slaton TL, Monz BU, et al. Development and validation of a patient satisfaction and preference questionnaire for inhalation devices. Treat Respir Med 2005;4:41-52.

152. Anderson P. Patient preference for and satisfaction with inhaler devices. Eur Respir Rev 2005;14:109-16.

153. Tottenborg SS, Lange P, Johnsen SP, et al. Socioeconomic inequalities in adherence to inhaled maintenance medications and clinical prognosis of COPD. Respir Med 2016;119:160-7.

154. Makela MJ, Backer V, Hedegaard M, Larsson K. Adherence to inhaled therapies, health outcomes and costs in patients with asthma and COPD. Respir Med 2013;107:1481-90.

155. Williams LK, Peterson EL,Wells K, et al. Quantifying the proportion of severe asthma exacerbations attributable to inhaled corticosteroid nonadherence. J Allergy Clin Immunol 2011;128:1185-91.

156. Delea TE, Stanford RH, Hagiwara M, Stempel DA. Association between adherence with fixed dose combination fluticasone propionate/salmeterol on asthma outcomes and costs. Curr Med Res Opin 2008;24:3435-42.

157. Suissa S, Ernst P, Benayoun S, et al. Low-dose inhaled corticosteroids and the prevention of death from asthma. N Engl J Med 2000;343 332-6.

158. Vestbo J, Anderson JA, Calverley PM, et al. Adherence to inhaled therapy, mortality and hospital admission in COPD. Thorax 2009;64:939-43.

159. Crompton GK, Barnes PJ, Broeders M, et al. The need to improve inhalation technique in Europe: A report from the Aerosol Drug Management Improvement Team. Respir Med 2006;100:1479-94.

160. Lavorini F, Magnan A, Dubus JC, et al. Effect of incorrect use of dry powder inhalers on management of patients with asthma and COPD. Respir Med 2008;102:593-604.

161. Giraud V, Roche N. Misuse of corticosteroid metered-dose inhaler is associated with decreased asthma stability. Eur Respir J 2002;19:246-51.

162. Molimard M, Raherison C, Lignot S, et al. Assessment of handling of inhaler devices in real life: An observational study in 3811 patients in primary care. J Aerosol Med 2003;16:249-54.

163. Sanchis J, Gich I, Pedersen S, et al. Systematic review of errors in inhaler use: Has patient technique improved over time? Chest 2016;150:394-406.
164. Rootmensen GN, van Keimpema AR, Jansen HM, de Haan RJ. Predictors of incorrect inhalation technique in patients with asthma or COPD: A study using a validated videotaped scoring method. J Aerosol Med Pulm Drug Deliv 2010;23:323-8.

165. Self TH, Arnold LB, Czosnowski LM, et al. Inadequate skill of healthcare professionals in using asthma inhalation devices. J Asthma 2007;44:593-8.

166. Lavorini F, Mannini C, Chellini E, Fontana GA. Optimising inhaled pharmacotherapy for elderly patients with chronic obstructive pulmonary disease: The importance of delivery devices. Drugs Aging 2016;33:461-73.

167. Price D, Chrystyn H, Kaplan A, et al. Effectiveness of same versus mixed asthma inhaler devices: A retrospective observational study in primary care. Allergy Asthma Immunol Res 2012;4:184-91.

168. Bosnic-Anticevich S, Chrystyn H, Costello RW, et al. The use of multiple respiratory inhalers requiring different inhalation techniques has an adverse effect on COPD outcomes. Int J Chron Obstruct Pulmon Dis 2016;12:59-71.

169. Thomas M, Price D, Chrystyn H, et al. Inhaled corticosteroids for asthma: Impact of practice level device switching on asthma control. BMC Pulm Med 2009;9:1.

170. Lavorini F, Braido F, Baiardini I, et al. Interchangeable use of inhalers. A document of Italian Society of Allergy, Asthma and Clinical Immmunology (SIAAIC) \& Italian Society of Respiratory Medicine (SIMeR). Pulm Pharmacol Ther 2015;34:25-30.

171. Lavorini F, Corrigan CJ, Barnes PJ, et al. Retail sales of inhalation devices in European countries: So much for a global policy. Respir Med 2011;105:1099-103.

172. Sestini P, Cappiello V, Aliani M, et al. Prescription bias and factors associated with improper use of inhalers. J Aerosol Med 2006;19:127-36.

173. Giraud V, Allaert F-A, Roche N. Inhaler technique and asthma: Feasability and acceptability of training by pharmacists. Respir Med 2011;105:1815-22.

174. Basheti IA, Reddel HK, Armour CL, Bosnic-Anticevich SZ. Improved asthma outcomes with a simple inhaler technique intervention by community pharmacists. J Allergy Clin Immunol 2007;119:1537-8.

175. Takemura M, Mitsui K, Ido M, et al. Effect of a network system for providing proper inhalation technique by community pharmacists on clinical outcomes in COPD patients. Int $\mathrm{J}$ Chron Obstruct Pulmon Dis 2013;8:239-44.

176. Hardwell A, Barber V, Hargadon T, et al. Technique training does not improve the ability of most patients to use pressurised metered-dose inhalers (pMDIs). Prim Care Respir J 2011;20:92-6.

177. Lavorini F, Levy ML, Corrigan C, et al. The ADMIT series - issues in inhalation therapy. Training tools for inhalation devices. Prim Care Respir J 2010;19:335-41.

178. Chrystyn H, Price D. Not all asthma inhalers are the same: Factors to consider when prescribing an inhaler. Prim Care Respir J 2009;18:243-9.

179. Dekhuijzen PN, Vincken W, Virchow JC, et al. Prescription of inhalers in asthma and COPD: Towards a rational, rapid and effective approach. Respir Med 2013;107:1817-21.

180. Bourbeau J, Bartlett SJ. Patient adherence in COPD. Thorax 2008;63:831-8.

181. DiMatteo MR. Variations in patients' adherence to medical recommendations: a quantitative review of 50 years of research. Med Care 2004;42:200-9.

182. Corden ZM, Bosley CM, Rees PJ, Cochrane GM. Home nebulized therapy for patients with COPD: patient compliance with treatment and its relation to quality of life. Chest 1997;112:1278-82. 
183. Turner J, Wright E, Mendella L, Anthonisen N. Predictors of patient adherence to long-term home nebulizer therapy for COPD. The IPPB Study Group. Intermittent Positive Pressure Breathing. Chest 1995;108:394-400.

184. Miller J, Edwards LD, Agusti A, et al. Comorbidity, systemic inflammation and outcomes in the ECLIPSE cohort. Respir Med 2013;107:1376-84.

185. Vanfleteren LE, Spruit MA, Groenen M, et al. Clusters of comorbidities based on validated objective measurements and systemic inflammation in patients with chronic obstructive pulmonary disease. Am J Respir Crit Care Med 2013;187:728-35.

186. Wilson IB, Schoen C, Neuman P, et al. Physician-patient communication about prescription medication nonadherence: a 50-state study of America's seniors. J Gen Intern Med 2007;22:6-12.

187. Col N, Fanale JE, Kronholm P. The role of medication noncompliance and adverse drug reactions in hospitalizations of the elderly. Arch Intern Med 1990;150:841-5.

188. Vanfleteren LE, Spruit MA, Wouters EF, Franssen FM. Management of chronic obstructive pulmonary disease beyond the lungs. Lancet Respir Med 2016;4:911-24.

189. Triest FJ, Franssen FM, Spruit MA, et al. Poor agreement between chart-based and objectively identified comorbidities of COPD. Eur Respir J 2015;46:1492-5.

190. Spruit MA, Singh SJ, Garvey C, et al. An official American Thoracic Society/European Respiratory Society statement: key concepts and advances in pulmonary rehabilitation. Am J Respir Crit Care Med 2013;188:e13-64.

191. Franssen FM, Rochester CL. Comorbidities in patients with COPD and pulmonary rehabilitation: do they matter? Eur Respir Rev 2014;23:131-41.

192. Crisafulli E, Costi S, Luppi F, et al. Role of comorbidities in a cohort of patients with COPD undergoing pulmonary rehabilitation. Thorax 2008;63:487-92.

193. Crisafulli E, Gorgone P, Vagaggini B, et al. Efficacy of standard rehabilitation in COPD outpatients with comorbidities. Eur Respir J 2010;36:1042-8.

194. Giardino ND, Curtis JL, Andrei AC, et al. Anxiety is associated with diminished exercise performance and quality of life in severe emphysema: a cross-sectional study. Respir Res 2010;11:29.

195. Garrod R, Marshall J, Barley E, Jones PW. Predictors of success and failure in pulmonary rehabilitation. Eur Respir J 2006;27:788-94.

196. von Leupoldt A, Taube K, Lehmann K, et al. The impact of anxiety and depression on outcomes of pulmonary rehabilitation in patients with COPD. Chest 2011;140:730-6.

197. Mesquita R, Vanfleteren LE, Franssen FM, et al. Objectively identified comorbidities in COPD: impact on pulmonary rehabilitation outcomes. Eur Respir J 2015;46:545-8.

198. Toy EL, Beaulieu NU, McHale JM, et al. Treatment of COPD: relationships between daily dosing frequency, adherence, resource use, and costs. Respir Med 2011;105:435-41.

199. Rolnick SJ, Pawloski PA, Hedblom BD, et al. Patient characteristics associated with medication adherence. Clin Med Res 2013;11:54-65.

200. Barnestein-Fonseca P, Leiva-Fernández J, Vidal-España F, et al. Is it possible to diagnose the therapeutic adherence of patients with COPD in clinical practice? A cohort study. BMC Pulm Med 2011;11:6.

201. Bourbeau J, Bartlett SJ. Patient adherence in COPD. Thorax 2008;63:831-8.

202. George J, Kong DC, Stewart K. Adherence to disease management programs in patients with COPD. Int J Chron Obstruct Pulmon Dis 2007;2:253-62.
203. Vestbo J, Anderson J, Calverley P, et al. Adherence to inhaled therapy, mortality and hospital admission in COPD. Thorax 2009;64:939-43.

204. Dhamane AD, Schwab P, Hopson S, et al. Association between adherence to medications for COPD and medications for other chronic conditions in COPD patients. Int J Chron Obstruct Pulmon Dis 2016;12:115-22.

205. Qian J, Simoni-Wastila L, Rattinger GB, et al. Association between depression and maintenance medication adherence among medicare beneficiaries with chronic obstructive pulmonary disease. Int J Geriatr Psychiatry 2014;29:49-57.

206. Hanania NA, Sharma G, Sharafkhaneh A. COPD in the elderly patient. Semin Respir Crit Care Med 2010;31:596-606.

207. Rogliani P, Ora J, Puxeddu E, et al. Adherence to COPD treatment: Myth and reality. Respir Med 2017;129:117-23

208. Izquierdo JL, Paredero JM, Piedra R. Relevance of dosage in adherence to treatment with long-acting anticholinergics in patients with COPD. Int J Chron Obstruct Pulmon Dis 2016;11:289-93.

209. Koehorst-ter Huurne K, Movig K, van der Valk P, et al. The influence of type of inhalation device on adherence of COPD patients to inhaled medication. Expert Opin Drug Deliv 2016;13:469-75.

210. Braido F, Lavorini F, Blasi F, et al. Switching treatments in COPD: implications for costs and treatment adherence. Int J Chron Obstruct Pulmon Dis 2015;10:2601-8.

211. Huetsch JC, Uman JE, Udris EM, Au DH. Predictors of adherence to inhaled medications among Veterans with COPD. J Gen Intern Med 2012;27:1506-12.

212. Osterberg L, Blaschke T. Adherence to medication. N Engl J Med 2005;353:487-97.

213. Trivedi RB, Bryson CL, Udris E, Au DH. The influence of informal caregivers on adherence in COPD patients. Ann Behav Med 2012;44:66-72.

214. Garcia-Aymerich J, Hernandez C, Alonso A, et al. Effects of an integrated care intervention on risk factors of COPD readmission. Respir Med 2007;101:1462-9.

215. Casas A, Troosters T, Garcia-Aymerich J, et al. Integrated care prevents hospitalisations for exacerbations in COPD patients. Eur Respir J 2006;28:123-30.

216. Tommelein E, Mehuys E, Van Hees T, et al. Effectiveness of pharmaceutical care for patients with chronic obstructive pulmonary disease (PHARMACOP): a randomized controlled trial. Br J Clin Pharmacol 2014;77:756-66.

217. van Boven JF, Tommelein E, Boussery K, et al. Improving inhaler adherence in patients with chronic obstructive pulmonary disease: a cost-effectiveness analysis. Respir Res 2014;15:66.

218. Leiva-Fernández J, Leiva-Fernández F, García-Ruiz A, et al. Efficacy of a multifactorial intervention on therapeutic adherence in patients with chronic obstructive pulmonary disease (COPD): a randomized controlled trial. BMC Pulm Med 2014;14:70.

219. Costello RW, Foster JM, Grigg J, et al. The seven stages of man: The role of developmental stage on medication adherence in respiratory diseases. J Allergy Clin Immunol Pract 2016;4:813-20.

220. WHO. Preventing chronic disease: a vital investment. WHO, Geneva, Switzerland; 2005.

221. IPASVI (Federazione Nazionale Collegi Infermieri professionali, Assistenti sanitari, Vigilatrici d'infanzia). [BPCO - Broncopneumopatia cronica ostruttiva]. Available from: http:// www.ipasvi.it/ per-il-cittadino/click-salute/bpco.broncopneumopatia-cronicaostruttiva-id9.htm

222. Zocchetti C, Merlino L, Agnello M, Bragato D. [Una nuova proposta per la cronicità: i CReG (Chronic Related Group)]. Tendenze Nuove; 2011. 
223. Amaducci S, Longo F, Nunziata F, Tasselli S. Innovative models of chronic care management: the case of Regione Lombardia. Shortness of breath 2013;2:131-7.

224. Roche N, Lepage T, Bourcereau J, Terrioux P. Guidelines versus clinical practice in the treatment of chronic obstructive pulmonary disease. Eur Respir J 2001;18:903-90.

225. Corrado A, Rossi A. How far is real life from COPD therapy guidelines? An Italian observational study. Resp Med 2012;106:989-97.

226. Cazzola M, Segreti A, Bettoncelli G, et al. Change in asthma and COPD prescribing by Italian general practitioners between 2006 and 2008. Prim Care Respir J 2011;20:291-8.

227. Cascini S, Kirchmayer U, Belleudi V, et al. Inhaled corticosteroid use in chronic obstructive pulmonary disease and risk of pneumonia: A nested case-control population-based study in Lazio (Italy) - The OUTPUL Study. COPD 2017;14:311-7.

228. Virchow JC, Crompton GK, Dal Negro R, et al. Importance of inhaler devices in the management of airway disease. Respir Med 2008;102:10-9.

229. Janssens W, VandenBrande P, Hardeman E, et al. Inspiratory flow rates at different levels of resistance in elderly COPD patients. Eur Respir J 2008;31:78-83.

230. Benfante A, Messina R, Milazzo V, Scichilone N. How to unveil chronic respiratory diseases in clinical practice? A model of alliance between general practitioners and pulmonologists. Pulm Pharmacol Ther 2017;44:106-10.

231. Rutschmann OT, Janssens JP, Vermeulen B, Sarasin FP. Knowledge of guidelines for the management of COPD: a survey of primary care physicians. Respir Med 2004;98: 932-7.

232. Scichilone N, Tuttolomondo A, Maida C, et al. Arterial stiffness in symptomatic smokers with normal lung function. ERJ Open Res 2017;3(3).pii: 00037-2017.

233. Battaglia S, Basile M, Spatafora M, Scichilone N. Are asthmatics enrolled in randomized trials representative of real-life outpatients? Respiration 2015;89:383-9.

234. Scichilone N, Basile M, Battaglia S, Bellia V. What proportion of chronic obstructive pulmonary disease outpatients is eligible for inclusion in randomized clinical trials? Respiration 2014;87:11-7.

\section{Index}

- Introduction (Claudio F. Donner)

\section{ASTHMA}

- Epidemiology of obstructive lung disease and adherence to treatment in asthma and COPD in Italy (Giovanni Viegi, Marzia Simoni, Sara Maio, Sandra Baldacci)

- Analysis of currently available inhalation drugs and personalized treatment in asthma (Elena Bacci, Manuela Latorre, Sara Brighindi, Maria Laura Bartoli, Silvana Cianchetti, Federico Lorenzo Dente, Alessandro Celi, Pier Luigi Paggiaro)

- Cost/benefit evaluation of different treatment approaches (Giorgio L. Colombo)

- Inhaler devices: A key role in the asthma personalized action plan (Dina Visca, Patrizia Pignatti, Antonio Spanevello)

- Adherence to asthma treatment: Myth and reality (Giuseppe U. Di Maria, Claudia Crimi, Annalisa Di Maria)

- Asthma: Toward a definition of the pillars of a correct therapeutic strategy (Roberto Torchio)

- Clinical and device preference comparisons of new versus old fixed-dose combination inhalers (David Price, Martina Stagno d'Alcontres, Shaylynn Yu Hui Xin, Shawna Tan)

\section{COPD}

- Analysis of currently available inhalation drugs in COPD (Lucio Casali)

- A real-life observational study on homeopathic medicine preventive effect in respiratory tract infections (Gianfranco Maria Beghi)

- The importance of inhaler device in COPD patient management (Federico Lavorini, Claudia Mannini, Massimo Pistolesi)

- Influence of comorbidities on adherence to treatment in COPD (Emiel F.M. Wouters)

- Medication adherence in patients with COPD (Mario Cazzola)

- Adherence to COPD therapy: The Lombardy CREG (Chronic Related Group) experience (Sandro Amaducci)

- State-of-the-art and open problems in COPD: Gaps and issues (Alida Benfante, Riccardo Messina, Daniela Castiglia, Nicola Scichilone) 